\title{
Laser Plasma Coupling for High Temperature Hohlraums
}

W. Kruer

November 4, 1999

U.S. Department of Energy

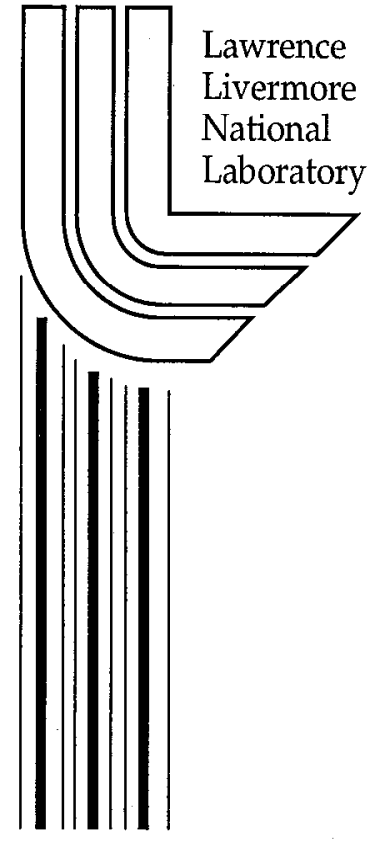




\section{DISCLAIMER}

This document was prepared as an account of work sponsored by an agency of the United States Government. Neither the United States Government nor the University of California nor any of their employees, makes any warranty, express or implied, or assumes any legal liability or responsibility for the accuracy, completeness, or usefulness of any information, apparatus, product, or process disclosed, or represents that its use would not infringe privately owned rights. Reference herein to any specific commercial product, process, or service by trade name, trademark, manufacturer, or otherwise, does not necessarily constitute or imply its endorsement, recommendation, or favoring by the United States Government or the University of California. The views and opinions of authors expressed herein do not necessarily state or reflect those of the United States Government or the University of California, and shall not be used for advertising or product endorsement purposes.

Work performed under the auspices of the U. S. Department of Energy by the University of California Lawrence Livermore National Laboratory under Contract W-7405-Eng-48.

This report has been reproduced

directly from the best available copy.

Available to DOE and DOE contractors from the

Office of Scientific and Technical Information

P.O. Box 62, Oak Ridge, TN 37831

Prices available from (423) 576-8401

http://apollo.osti.gov/bridge/

Available to the public from the

National Technical Information Service

U.S. Department of Commerce 5285 Port Royal Rd.,

Springfield, VA 22161

http://www.ntis.gov/

\section{OR}

Lawrence Livermore National Laboratory

Technical Information Department's Digital Library

http:/ /www.Ilnl.gov/tid/Library.html 


\section{An Overview of Coupling Physics Issues----W. Kruer}

Laser Plasma Coupling for High Temperature Hohlraums

Introduction and Overview

Simple scaling models 1 indicate that quite high radiation temperatures can be achieved in hohlraums driven with the National Ignition Facility. A scaling estimate for the radiation temperature versus pulse duration for different size NIF hohlraums is shown in Figure 1. Note that a radiation temperature of about $650 \mathrm{ev}$ is projected for a so-called scale 1 hohlraum (length $2.6 \mathrm{~mm}$, diameter $1.6 \mathrm{~mm})$. With such high temperature hohlraums $2-4$, for example, opacity experiments could be carried out using more relevant high $\mathrm{Z}$ materials rather than low. $\mathrm{Z}$ surrogates. These projections of high temperature hohlraums are uncertain, since the scaling model does not allow for the very strongly-driven laser plasma coupling physics. Lasnex calculations ${ }^{5}$ have been carried out to estimate the plasma and irradiation conditions in a scale 1 hohlraum driven by NIF. Linear instability gains as high as $\exp (100)$ have been found for stimulated Brillouin scaltering, and other laser-driven instabilities are also far above their thresholds. More understanding of the very strongly-driven coupling physics is clearly needed in order to more realistically assess and improve the propects for high temperature hohlraums. Not surprisingly, this regime has been avoided for inertial fusion applications and so is relatively unexplored.

Fortunately, there is reason to be hopeful. Recent high temperature hohlraum experiments on Nova 2,3 have indicated tolerable coupling, even though quite strongly driven. It is noteworthy that a scale .25 hohlraum irradiated with Nova has plasma and irradiation conditions quite similar to those in a scale 1 hohlraum irradiated with NIF. The key issue then becomes how this coupling scales to a 4 times larger hohraum. Recently a nonlinear scaling model 6 has been proposed which helps us to better understand the Nova experiments and suggests a more benign scaling with plasma size than models based on linear theory. We will recommend some more detailed calculations and related experiments to help us better understand this coupling regime and determine appropriate control mechanisms. 
Plasmas conditions and coupling physics issues

It is instructive to estimate the plasma conditions in high temperature hohlraums. Let's begin with the NIF point design for inertial fusion applications. the hohlraum has a peak radiation temperature of $300 \mathrm{ev}$. To minimize laser-driven instabilities, the design is restricted to a plasma fill density of about $.1 \mathrm{n}_{\mathrm{cr}}$, the laser intensity is limited to about $2 \times 10^{15} \mathrm{~W} / \mathrm{cm}^{2}$, and laser beam smoothing by SSD is employed. Higher temperature hohlraums will fill with plasma to a higher density, since more material is ablated by $x$-rays from the hohlraum walls. Estimating that the plasma density $n_{e}$ scales as the $x$-ray mass ablation rate gives ${ }^{7}$ that $n_{e} \alpha T_{r}^{1.86}$. Hence for a radiation temperature significantly greater than $300 \mathrm{ev}$, the hohlraum will fill to $.25 \mathrm{n}_{\mathrm{cr}}$ and beyond.

To be specific, let's consider a scale 1 Au hohlraum (length $=2.5 \mathrm{~mm}$, diameter $=1.6 \mathrm{~mm}$ ) driven by a $500 \mathrm{TW}$ NIF pulse. If we assume that $40 \%$ of the wall area is irradiated, the intensity $\mathrm{I} \sim 10^{16} \mathrm{~W} / \mathrm{cm}^{2}$. Using the scaling discussed above, we estimate a fill plasma density of $\sim .4 n_{c r}$. The temperature of this Au fill plasma is estimated by balancing the inverse bremmsthralung absorption with the electron heat flow ${ }^{8}$, giving

$$
\mathrm{T}_{\mathrm{e}} \sim\left(22 \mathrm{ZL}\left(\mathrm{I} / 2 \times 10^{13}\right) \mathrm{n} / \mathrm{n}_{\mathrm{cr}}\right)^{.333 .}
$$

This temperature is about $15 \mathrm{kev}$.

Improved values for the plasma conditions can be obtained from Lasnex calculations by Linda Powers ${ }^{5}$. Hohlraums with scale sizes from .5 to 3.5 were irradiated with $500 \mathrm{TW}, 3$ ns pulses. The beams were configurcd into inner and outer cones as shown in Figure 2. A characteristic density and temperature of the fill plasma at time of peak radiation temperature is shown in Figure 3. The point design for inertial fusion corresponds to scale 3.5 , with density near $.1 \mathrm{n}_{\mathrm{cr}}$ and temperature near $5 \mathrm{kev}$. In contrast, a scale 1 high temperature hohlraum has a fill plasma density of about $.3 n_{c r}$ with an electron temperature of about $20 \mathrm{kev}$.

These Lasnex calculations do not allow for any degradation of the absorption due to laser-driven instabilities. This assumption can be tested by using a post-processor code LIP $^{9}$, which calculates the linear gain coefficients for stimulated Brillouin and Raman scattering and laser beam filamentaion. The local spatial gain rate for these instabilities is integrated along a central ray path using the Lasnex-generated plasma and irradiation 
conditions. Characteristic gain exponents for SBS, SRS, and the filamentation gain per speckle are shown in Figure 4 as a function of hohlraum scale size. Note that for a scale 1 hohlraum driven with NIF, the gain exponent for SBS is nearly 100. Filamentation and SRS are also significantly above threshold.

How long should the Lasnex calculations be trusted? This so-called lifetime is quite dependent on the failure assumptions. Figure 5 shows Lasnex-calculated lifetimes as a function of scale size, displaying various criteria ranging from filling with plasma to a density of $.3 n_{c r}$ to reaching an SBS gain coefficient of 40 . Improved understanding of the very strongly-driven coupling physics will enable us to better determine and control the actual constraints.

High temperature hohlraum experiments with Nova and nonlinear scaling

Initial Nova experiments ${ }^{2,3}$ to explore higher temperature hohlraums provide grounds for cautious optimism. In these experiments, hohlraums with scale sizes ranging from 1 to .25 were irradiated with 10 beams with a 1 ns pulse length and a total power of about $25 \mathrm{TW}$. According to Lasnex calculations, a scale .25 hohlraum driven by Nova has about the same plasma and irradiation conditions as a scale 1 driven by NIF. For example, the fill density at time of peak radiation temperature is about $.4 \mathrm{n}_{\mathrm{cr}}$ and the electron temperature is about $20 \mathrm{kev}$. Of course, the size of the plasma differs by a factor of 4 .

Significant but tolerable levels of SBS and SRS were observed in these Nova experiments. The most detailed information ${ }^{3}$ is available for scale $5 / 8$ and scale $3 / 4$ hohlraums; this is shown in Table 1. Although the instabilities were nominally strongly driven, the SRS reflectivity was $<15 \%$ for an unsmoothed laser beam and $<3-7 \%$ for a beam smoothed with a random phase plate. The SBS reflectivity was $<3-5 \%$ in either case. When SRS energy losses were taken into account, the measured and calculated hohlraum temperatures were in reasonable agreement.

These results are very encouraging. The key question becomes: what is the scaling to NIF? To help understand these strongly-driven Nova experiments and their scaling to NIF, a nonlinear scaling model has been recently proposed ${ }^{6}$. This scaling model assumes that the correlation length for stimulated scattering is set nonlinearly by laser beam filamenation and that the different scattering regions are decorrelated, as suggested by recent calculations invoking modified electron distributions. Although very idealized, the model is consistent with a number of experimental results on 
the scaling of SBS with intensity, plasma density and scale length, and with the f/number of the focussing optic. See the attached paper for more details and for some addtional advanced applications requiring a better understanding of very strongly-driven coupling.

Next steps

For high temperature hohlraums, we are accessing a relatively unexplored regime of laser plasma coupling. The hohlraums fill with high $\mathrm{Z}$ plasma with density $.25 \mathrm{n}_{\mathrm{cr}}$ and with electron temperature $>15 \mathrm{kev}$. The laser intensity can be quite high; $1>10^{16} \mathrm{~W} / \mathrm{cm}^{2}$. Near $.25 \mathrm{n}_{\mathrm{cr}}$, stimulated Raman scattering can be potent. More generally, stimulated Brillouin scattering and filamentation are very strongly driven. We also predict that the heated electron distributions will be significantly changed from Maxwellian distributions.

New calculations and related experiments are needed to better understand and control the coupling physics restraints. Let's give a few examples. Simulations using a $2 \mathrm{D}$ hybrid particle-in-cell code such as $\mathrm{BZOHAR}^{10}$ can quantify the competition between stronly-driven SBS and filamentation and improve our model for the nonlinear correlation length for stimulated scattering. Comparison with filamentation codes such as F3D ${ }^{11}$ can help us to better mock up non-paraxial and kinetic effects in these reduced descriptions. Fokker-Planck calculations of the collisional heating and heat transport can better quantify the modified electron distributions ${ }^{12}$. Such distributions can both change the inverse bremssthralung absorption coefficient by a factor of 2 (an effect already in Lasnex) and decorrelate the different scattering regions (an effect assumed in the nonlinear scaling model). Finally, calculations using particle-in-cell codes with collisions (developed by P. Rambo ${ }^{13}$ ) can more accurately determine the ion temperature including the effects of interpenetration and the ion wave damping in the fill plasma.

It would be very valuable to examine the strongly-driven regime in well-diagnosed experiments using the Janus laser. These experiments would be a natural follow-on to the many productive experiments which helped us to better understand the lower density plasma regime more relevant to inertial fusion. For example, Janus proved to be an extremely productive testbed for investigating both nonlinear beam bending ${ }^{14}$ and laser beam spraying due to filamentation ${ }^{15}$. As one example, these experiments have a sufficiently simple geometry that we could compare in detail the measurements with simulations of strongly-driven SBS and filamentation 
More experiments with smaller hohlraums could be carried with either Nova or Omega. These experiments could address the benefits of beam smoothing and low $\mathrm{Z}$ fill plasmas in the strongly-driven regime. Likewise, spatially-imaged measurements of the $3 / 2 \omega_{0}$ and the $2 \omega_{0}$ emission could test our calculations of hohlraum filling and assess the role of interpentrating plasmas. Finally, hohlraums which fill to near $.25 \mathrm{n}_{\mathrm{cr}}$ could test our calculations of strongly-driven SRS and-as a bonus-help develop $\mathrm{X}$-ray sources for other advanced applications ${ }^{6}$. 


\section{References}

1. O.L.Landen, Scaling for Hohlraum Limits, Memorandum (1998) and refences therein

2.P.T.Springer, L.J.Suter, and W.H.Goldstein, Experiments to Investigate High Temperature Hohlraum Production on Nova and NIF, Proceedings of the 1996 NEDC (1996)

3.T.J.Orzechowski et. al., Energetics of small high-temperature, laserdriven hohlraums, 26th Anomalous Absorption Conference (1996)

4.R.L.Lee, R. Petrasso, and R.W. Falcone, Science on High-Energy Lasers: From Today to NIF, UCRL-ID-119170 (1995)

5.L.V.Powers et. al., Radiation Temperature Scaling in Hohlraums for Nova and NIF, 24th European Conference on Laser Interaction with Matter (1996)

6. W.L.Kruer et. al., Strongly-Driven Laser Plasma Coupling, UCRL-JC130610 (1998)

7.John D. Lindl, Inertial Confinement Fusion (Springer-Verlag, New York, 1998)

8.E.M.Campbell et al., The $.53 \mu$ Laser Option for Inertial Fusion, Comments Plasma Phys. Controlled Fusion 18,201(1997)

9. R.L.Berger,private communication 10.B.I.Cohen, B.F. Lasinski, A.B. Langdon, and E.A. Williams, Phys. Plasmas 4,956(1997)

11.R.L.Berger et. al., Phys. Fluids B5,2243(1993)

12.B.B.Afeyan et. al., Phys. Rev. Letters 80,2322(1998)

13. P.W. Rambo, S.C. Wilks, and W.L.Kruer, Phys. Rev. Letters 79,83(1997)

14. P.E.Young et. al., Phys. Rev Letters (in press)

15. S.C. Wilks et. al., Phys. Rev. Letters 73,2954(1994) 


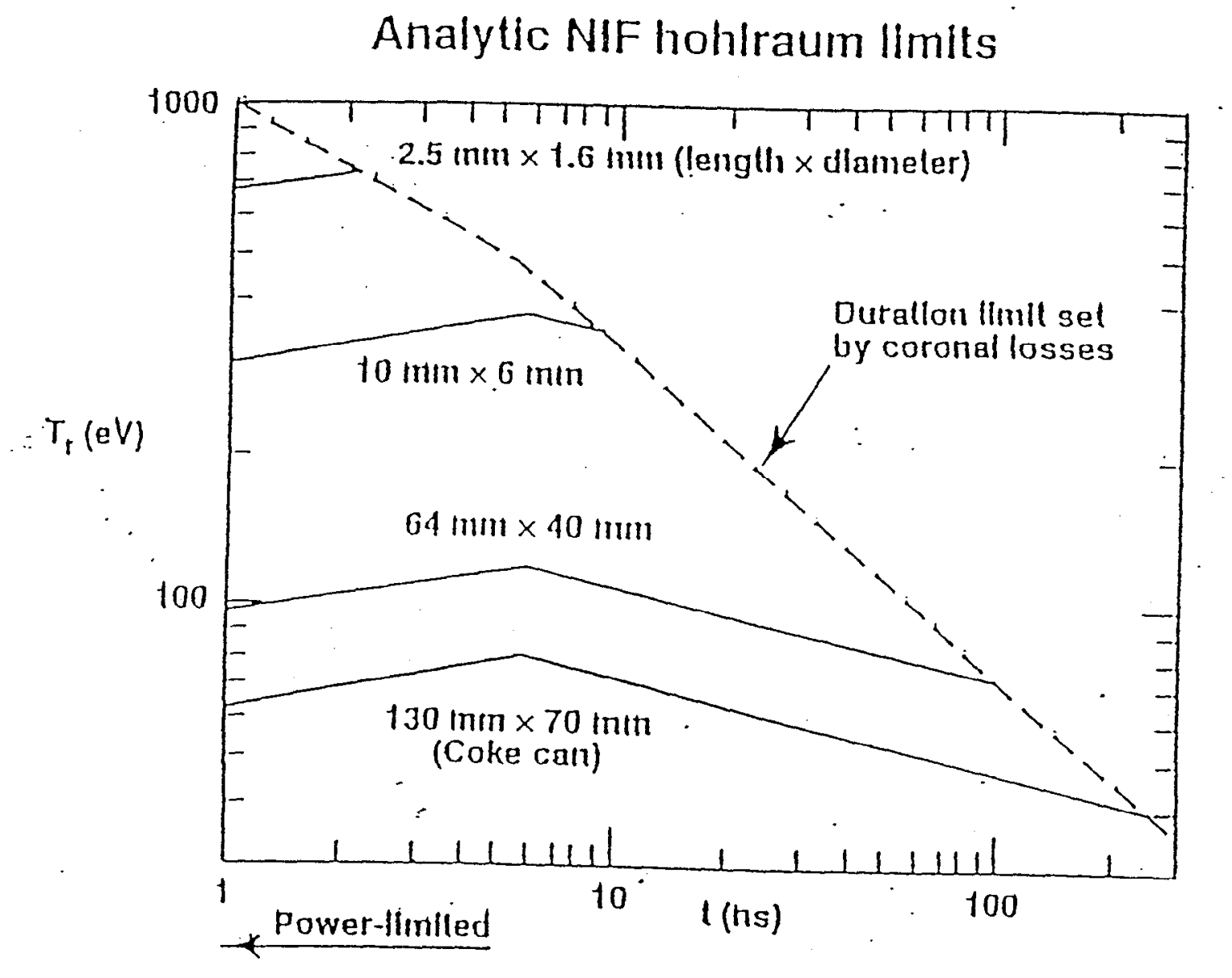

Eliergy-linlted (Beam slaggerlig) $\longrightarrow$

Figure 1. Scaling estimates for the radiation temperature versus laser pulse length for hohraums of various sizes driven by NIF. 


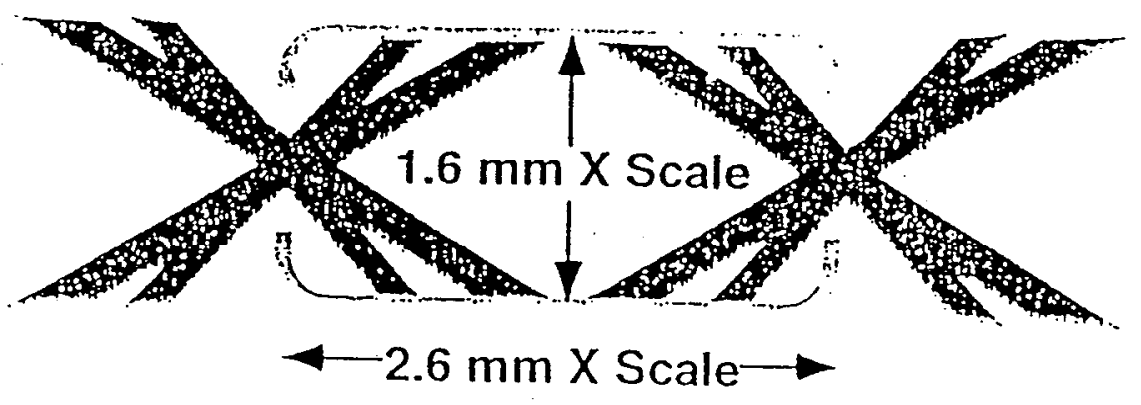

Figure 2. A schematic of the hohlraum and the irradiation scheme used in the Lasnex calculations. A 500 TW, 3 ns laser puser in 48 

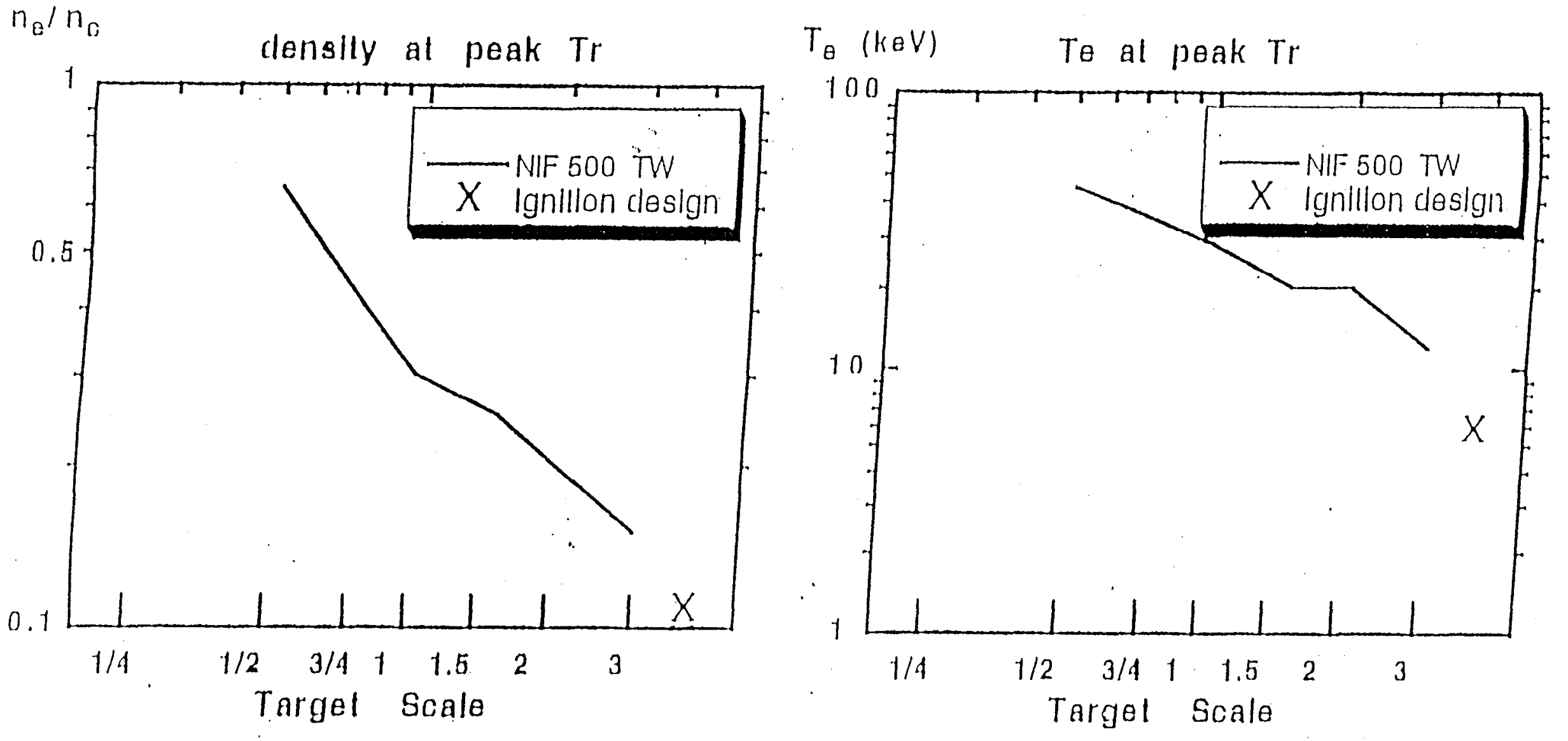

Figure 3. Lasnex calculations of the density and electron temperature of the plasma filling the hohlraum at the time of peak radiation temperature as a function of the hohlraum scale size. 


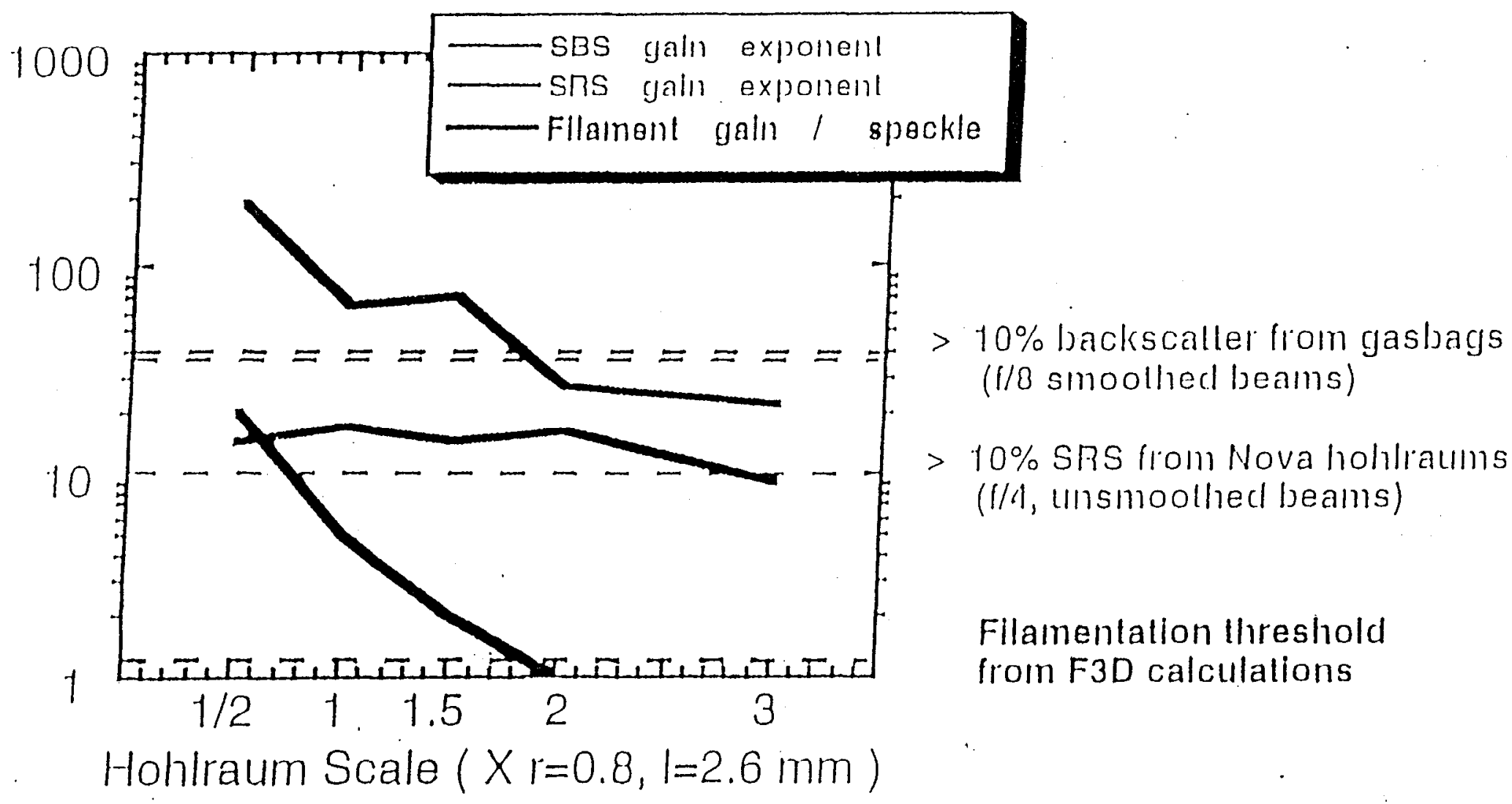

Figure 4. Laser-driven instability gain exponents calculated with the post-processor LIP at the time of peak radiation temperature as a function of the hohlraum scale size. 


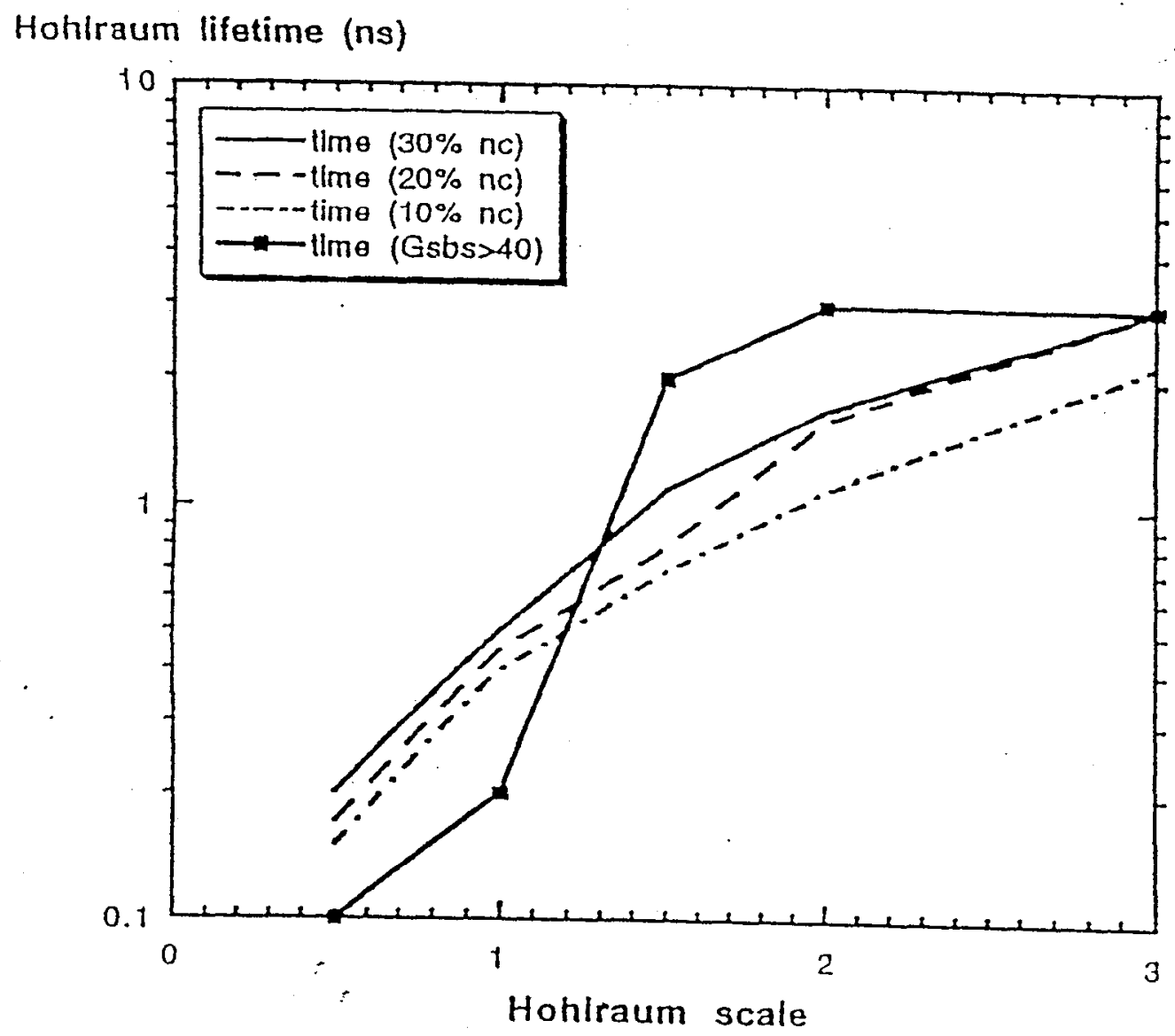

Figure 5. Lasnex-calculated hohlraum lifetimes versus scale size based on various failure assumptions. 


\begin{tabular}{|c|c|c|c|c|c|c|}
\hline ohlraum slze/focus & $T_{\text {wnIl }}$ & $T_{1101}$ & $E_{1101}$ & $E_{L}$ & $E_{s 10} / b e$ & $E_{\text {sus }} /$ bea \\
\hline cale-1/LEH & $241 \mathrm{eV}$ & $41 \mathrm{keV}$ & $510 \mathrm{~J}$ & $20 \mathrm{~kJ}$ & $437 \mathrm{~J}$ & $32 \mathrm{~J}$ \\
\hline scale-1/N-plate & $243 \mathrm{eV}$ & $36 \mathrm{keV}$ & $422 \mathrm{~J}$ & $27 \mathrm{~kJ}$ & $26 \mathrm{~J}$ & $32 \mathrm{~J}$ \\
\hline gcale-3/4/LEH & $273 \mathrm{eV}$ & $36 \mathrm{keV}$ & $1.3 \mathrm{~kJ}$ & $20 \mathrm{~kJ}$ & $455 \mathrm{~J}$ & $78 \mathrm{~J}$ \\
\hline scale- $3 / 4 /(p$-plate & $261 \mathrm{eV}$ & $30 \mathrm{keV}$ & $050 \mathrm{~J}$ & $20 \mathrm{~kJ}$ & $40 \mathrm{~J}$ & $76 \mathrm{~J}$ \\
\hline scale-5/8/LEF & $202 \mathrm{eV}$ & $40 \mathrm{keV}$ & $1.3 \mathrm{~kJ}$ & $29 \mathrm{~kJ}$ & $394 \mathrm{~J}$ & $140 \mathrm{~J}$ \\
\hline scale-5/0/N-plate & $279 \mathrm{eV}$ & $40 \mathrm{keV}$ & $1.0 \mathrm{~kJ}$ & $29 \mathrm{~kJ}$ & $175 \mathrm{~J}$ & $90 \mathrm{~J}$ \\
\hline
\end{tabular}

Table 1. Representative measurements of the radiation temperature ( $T_{\text {wall }}$ ), the energy in hot electrons (Ehot) with temperature Thot, and the energy in Raman-scattered and Brillouin-scattered light (Esrs andEsbs). 


\author{
BILL KRUER \\ X-DIVISION / DNT / LLNL
}

X WORK IN PROGRESS

* JULY 28, 1998 


\section{Some references are}

\section{Applications of High-Power Lasers to Science-Based Stockpile Stewardship (U) 1996 CLY-96-0037}

\section{L.J. Suter, L.V. Powers, J.H. Hammer, T.J. Orzechowski, P.T. Springer, and O.L. Landen}

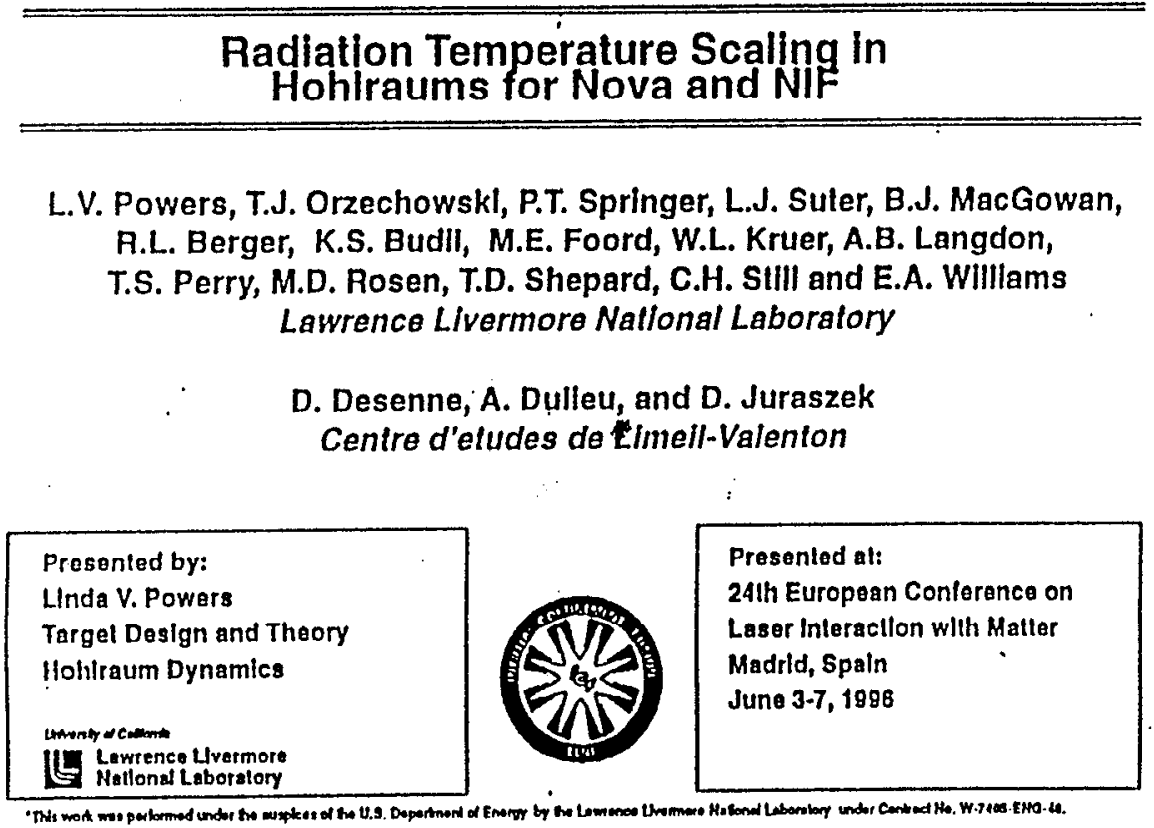

\begin{tabular}{c}
\hline \hline Energetics of small, \\
high-temperature, laser-driven \\
hohlraums
\end{tabular}

T. J. Orzechowskl, B. B. Aleyan, R. L. Berger, M. A. Blaln, R. K. Klrkwood, H. N. Kornblum, W. L. Kruer, B. J. MacGowan, J. D. Moody, L. V. Powers, M. D. Rosen, P. T. Springer, L. J. Suter, R. L. Wallace

园

Presented at the $26^{\text {a }}$ Anomalous Absorpllon Conference Fairbanks, AK 26-30 Augusl, 1996

Thle work perlormed under the suspices of the U. S. DOE by the Lewronce Llvermore Nallonal Laboratory under contract 
Some references are -LLNL

Experiments to Investigate High Temperature Hohlraum Production on Nova and NIF (U), 1996 P.T. Springer, L.J. Suter, and W.H. Goldstein

Scaling for Hohlraum Limits Memo,1998 O.L. Landen and references therein to AWE, Lindl, Rosen,...

Science on High-Energy Lasers: From Today to the NIF UCRL-ID-119170, 1995

R.L. Lee, R. Petrasso, R.W. Falcone 
Outline of Presentation $-L L N L$

* Nova experiments and scaling models indicate that higher temperature hohlraums are possible with NIF; these are valuable for SSMP

* Strongly-driven laser plasma interaction physics is a key issue for attaining higher temperature hohlraums

* Nova experiments and recent theory are hopeful: next steps are outlined 


\section{Applied High Energy Density Science Problems: II. Weapons Physics}

Laboratory experiments test meapons physics issues

Weapons physics scallng
Weapons physics and related stockpile stewardship experiments carried out on ICF facilities are collaborative efforts carried out by ICF and weapons program personnel. The role played by the ICF Program is generally twofold: (1) to expand the range of high energy density plasma conditions (hohlraum temperanure; plasma lifetime, density, and temperature) accessible in the laboratory, and (2) to define new experimental geometries, techniques, and diagnostics that facilitate stewardship experiments. Laboratory experiments to test particular weapons issues are then carried out in collaboration with weapons program scientists.

Similar to ignition physics, weapons physics experiments on ICF facilities involve the study of both basic and applied high energy density science problems. Some of these experiments will be proof of principle efforts for larger scale experiments on funure ICF program facilities that will be carried out in a regime more comparable to weapon conditions. In particular, the scaling of these experiments to NIF and potential future pulsed power facilities is of high priority, as these capabilities will be required in the near term to maximize the urility of the ICF Program to stockpile stewandship.

Plans for fundamental high energy density science research relevant to weapons include:

Hydrodynamies. Planar experiments on Nova. Omega, and Nike will investigate the transition to turbulence. The formation of jets will be studied using hemispherical and other targets.

Atomic Physics and Radiative Properties. Measurements of mid- $Z$ material opacity will continue on Nova and PBFA Z and begin on Nike. Preparatory work for NIF opacity experiments such as $x$-ray backlighter development will also continue. New atomic physics modeling capabilities are under development at LLNL LANL. and NRL.

Material Properties and Equation of State. Methods for measuring on- and offHugoniot equations of state to the few percent accuracy required to differentiate between theories will be developed. The use of flyer plate techniques to achieve very high pressures (pressures near $~ 1$ Gbar have been observed to date) will be explored.

Plasma Physics. Plasma physics issues relevant to important goals, such as the achievement of hohiraums with temperanures greater than $300 \mathrm{eV}$, will be investigated.

Computational Physics. The ICF Program will continue development of advanced three-dimensional simulation codes, as described further below.

Specific applied problems to be considered include:

High temperature hohlraum development. Hohlraums with drive temperatures well in excess of $300 \mathrm{eV}$ are of interest to the weapons program for hydrodynamic studies and other experiments; efforts to develop such radiation environments will be carried out on Nova. 


\section{The NIF will explore a wide range of hohlraum sizes and temperatures}

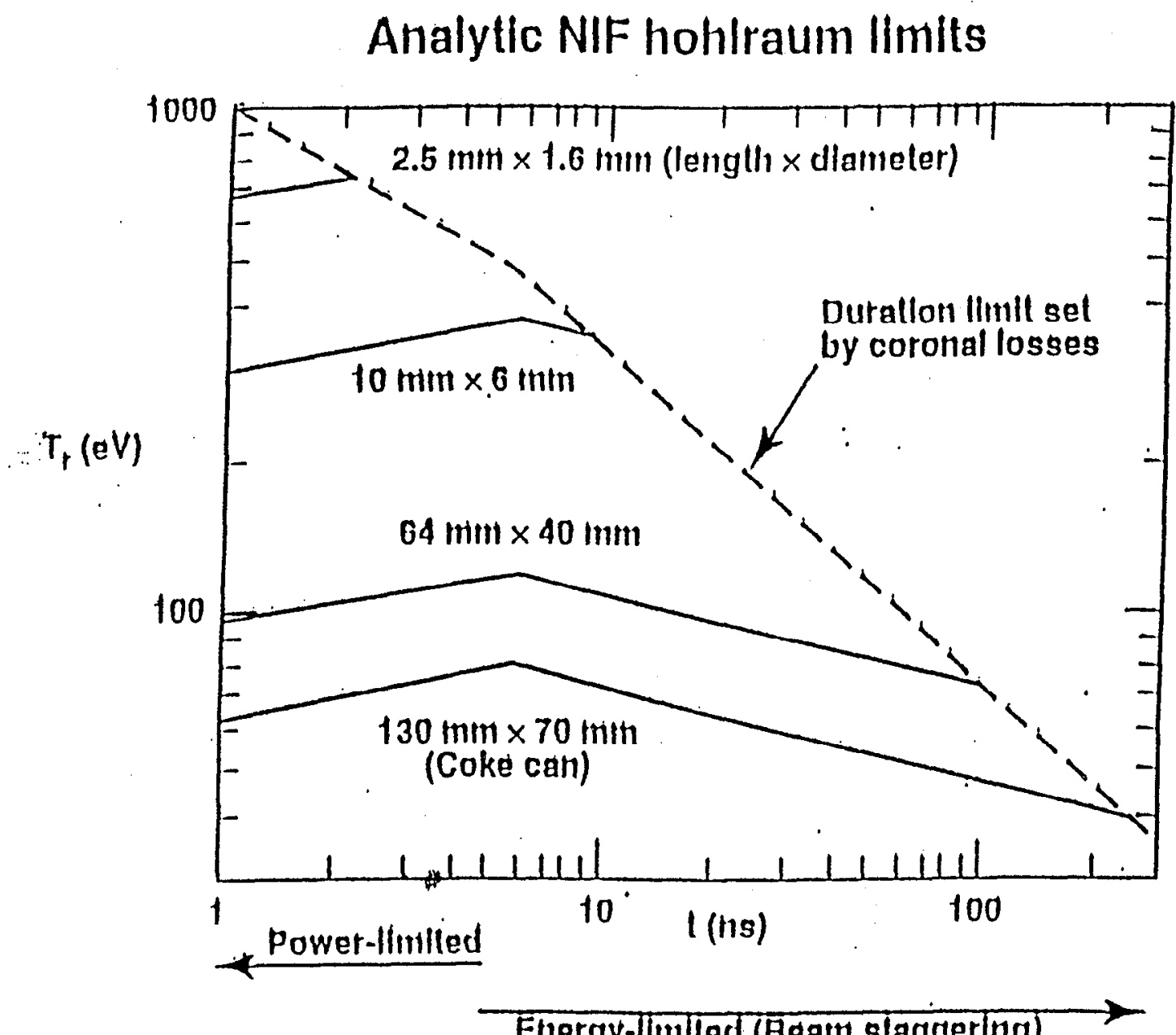




\section{Outline of Presentation}

* Nova experiments and scaling models indicate that higher temperature hohlraums are possible with NIF; these are valuable for SSMP

*Strongly-driven laser plasma interaction physics is a key issue for attaining higher temperature hohlraums

*Nova experiments and recent theory are hopeful: next steps are outlined 


\section{The Big Picture}

Collisional Coupling

Nonlinear Coupling

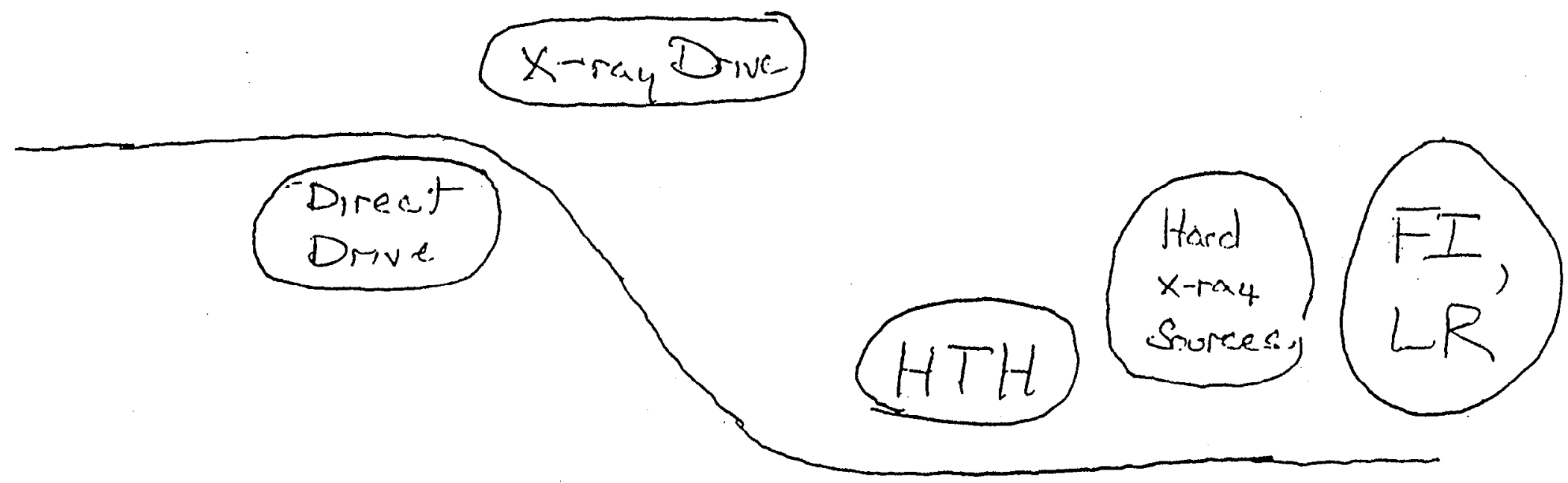

$$
\text { " } \lambda, I, L, \text { or } n_{e}
$$

Mainline ICF: stay to the left

Many advanced applications are to the right 
Nonlinear coupling physics is needed for high temperature hohlraums

$$
\mathrm{n}_{\mathrm{e}} \sim \mathrm{T}_{\mathrm{r}}^{1.86} \quad \text { JDL Eq.7-28 }
$$

NIF point design $\quad$ SRS, $2 \omega_{\text {pe }} \quad$ SBS,FIL
$\mathrm{n}_{\mathrm{e}}=.1 \mathrm{n}_{\mathrm{cr}}, \mathrm{T}_{\mathrm{e}}=5 \mathrm{kev}$
$.25 n_{\text {cr }}$
$>.25 \mathrm{n}_{\mathrm{cr}}$

$\mathrm{SSD}, \mathrm{I}=2 \times 10^{15} \mathrm{~W} / \mathrm{cm}^{2} \quad$ Bonus-hard

$x$-rays

$300 \mathrm{ev}$

- $\mathrm{T}_{\mathrm{r}}$


Simple estimate of plasma conditions in NIF Scale $1 \mathrm{HTH}$

Scale $12.5 \mathrm{~mm} \times 1.6 \mathrm{~mm}$

1.

$$
I \sim \frac{500 \mathrm{TW}}{.4(.04 \pi) \mathrm{cm}^{2}} \sim 10^{16 \mathrm{~W} / \mathrm{cm}^{2}}
$$

2. $n_{e} \propto T_{r}^{1.86}$

scales as areal mass density ablation by $x$-rays

3.

$$
\begin{aligned}
& T_{e} \simeq\left[22.2\left[{\frac{I}{2 \times 10^{13}}}_{\frac{n}{n_{e r}}}\right]^{1 / 3} \quad \begin{array}{l}
\text { Inverse bremssthralong } \\
\text { heating }
\end{array}\right. \\
& \begin{aligned}
1,2 \text { and } 3 \rightarrow \quad n_{e} \simeq .04 n_{\text {or }} \\
T_{e} \simeq 15 \text { btu }
\end{aligned}
\end{aligned}
$$




\section{Lasnex calculations have been used to estimate the plasma conditions for high temperature hohlraums}

We have begun to evaluate a range of NIF hohlraum designs at small target size and high laser power

Target:

Scales $1 / 2,1,1.5,2,3$

$(X r=0.8 \mathrm{~mm}, 1=2.6 \mathrm{~mm})$

Laser:

500 TW / 3ns in 48 beams

Inner cone spotsize $=\mathrm{D}_{\mathrm{lel}} / 2$

Outer cone spolsize $=D_{\text {let }} / 3$

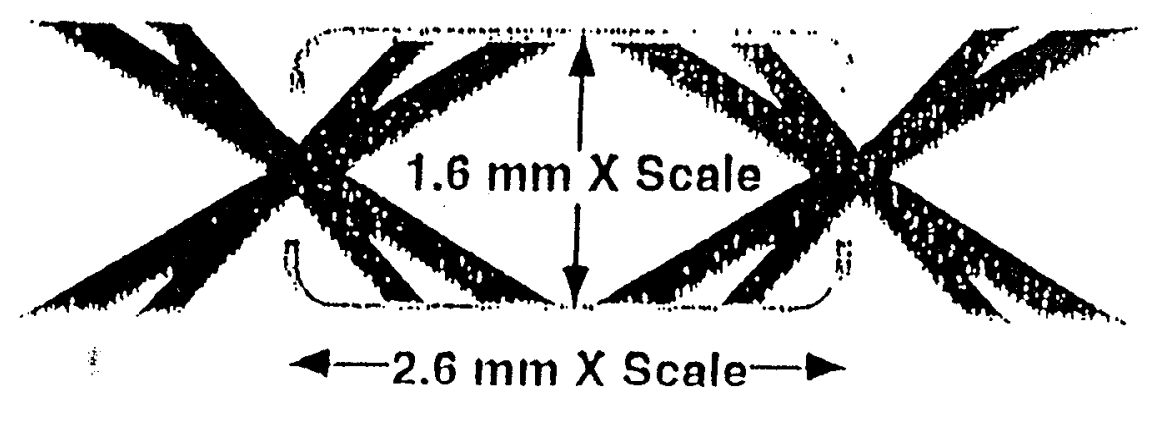

The fill plasma in these taigets is hot and dense by the time of peak radiation flux

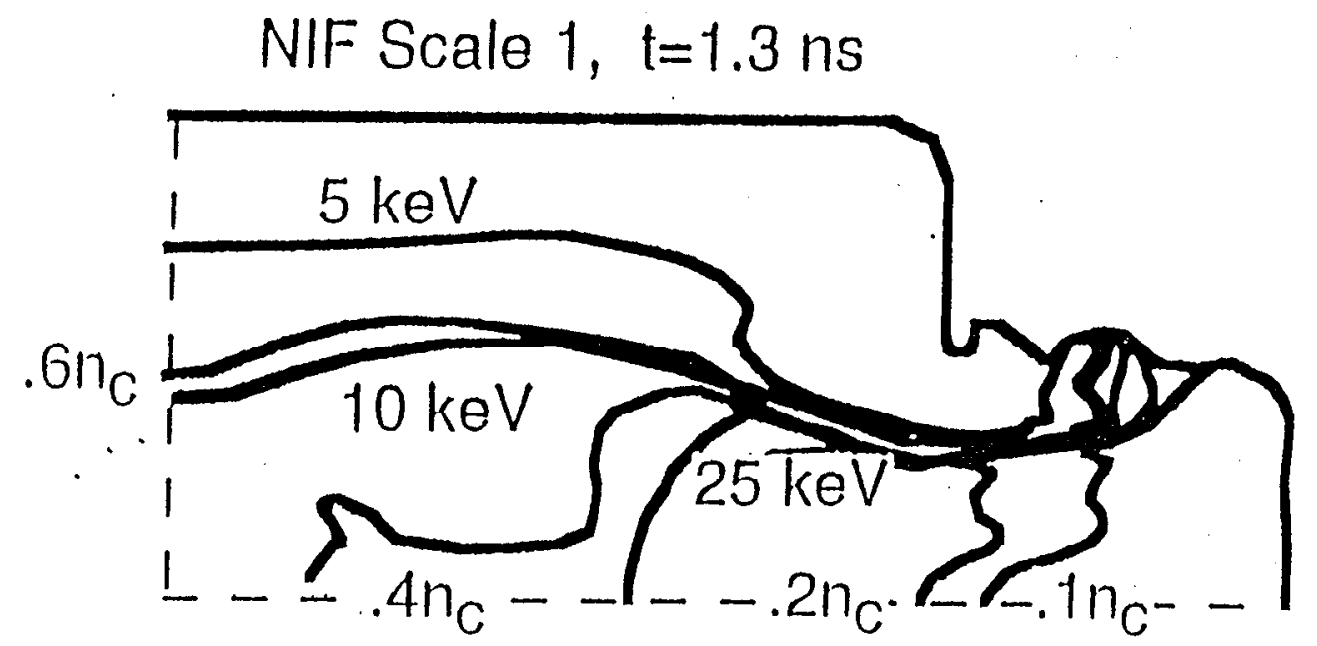


NIF high temperature hohlraums fill with hot plasma with density $\geq .25 \mathrm{n}_{\text {cr }}$

\section{- LLNL}
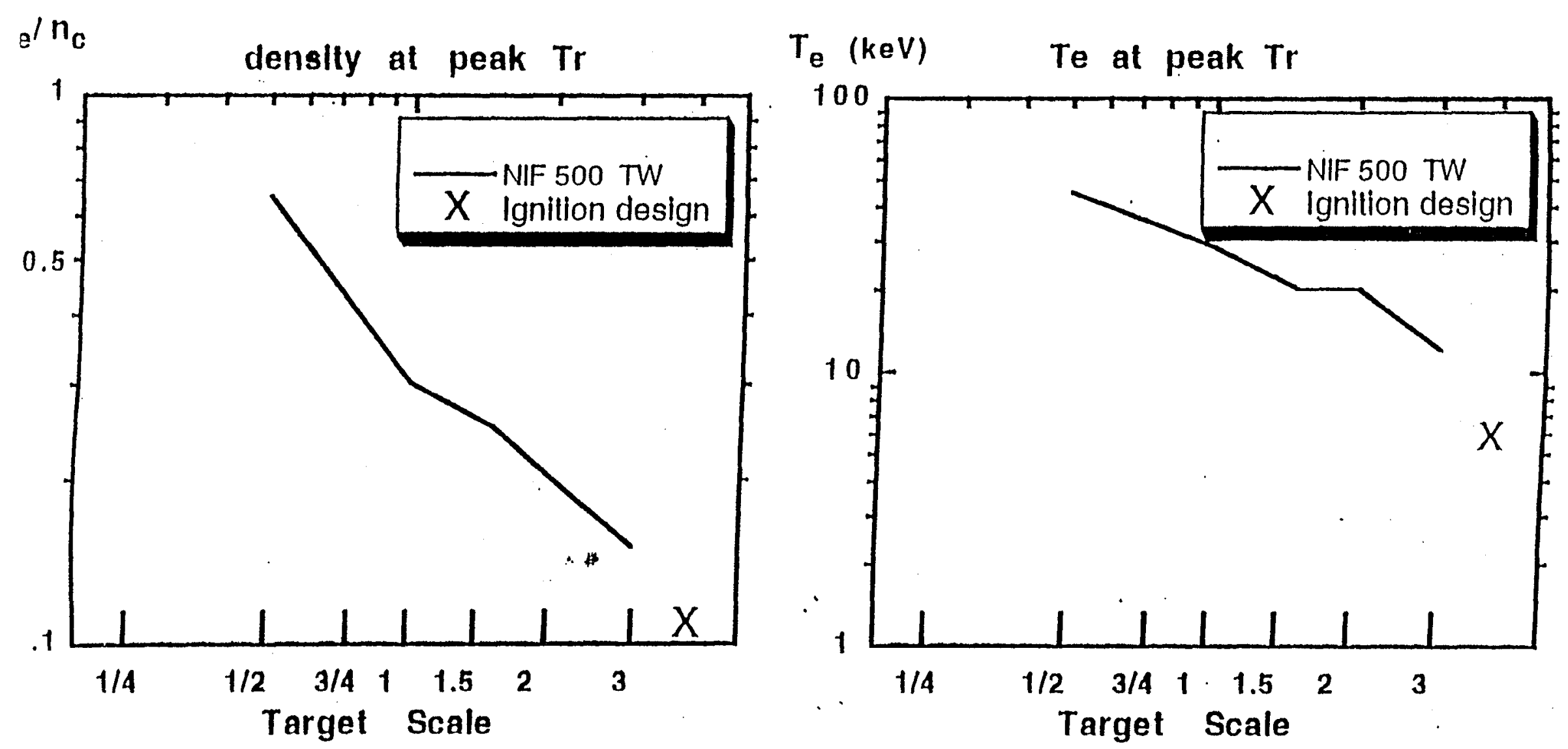

Powers 


\section{We use the calculated linear gain exponents and associated SRS and SBS reflectivities to assess the probability of significant parametric instabilities}

We integrate the local spatial gain rate calculated from simulation parameters along the path of the scattered light to obtain the intensity gain exponent

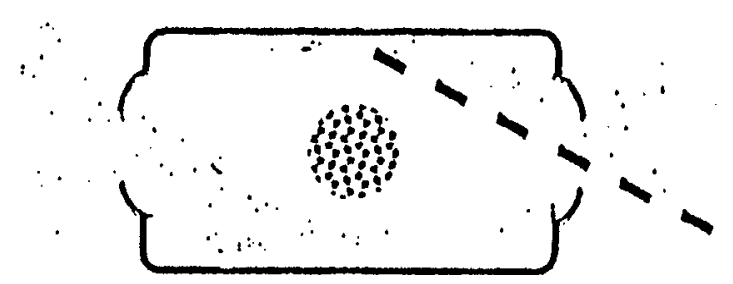

$$
G\left(\omega_{s}\right)=\int^{\text {palh }} d z \frac{\left(k_{0}-k_{s}\right)^{2} v_{0}{ }^{2}}{4 \omega_{0} v_{g}} \operatorname{lm}\left(\frac{\left(1+x_{i}\right) \chi_{e}}{1+x_{i}+\chi_{e}}\right)
$$

The LIP calculation includes:

- kinetically correct growth gates

- multi-species ion damping

- intensity variations due to Inverse Bremsstrahlung absorption and beam divergence

- $\quad$ pump depletion limit on reflectivities

LIP does not treat

- nonlinear saturation /pdetuning

- beam coherence effects (speckles, temporal smoothing)

Complementary modeling and analysis techniques are used to investigale effects not included in this simple treatment 


\section{In small NIF hohlraums driven with 500 TW power, calculated gains for SBS and filamentation are well above thresholds estimated from experiment}

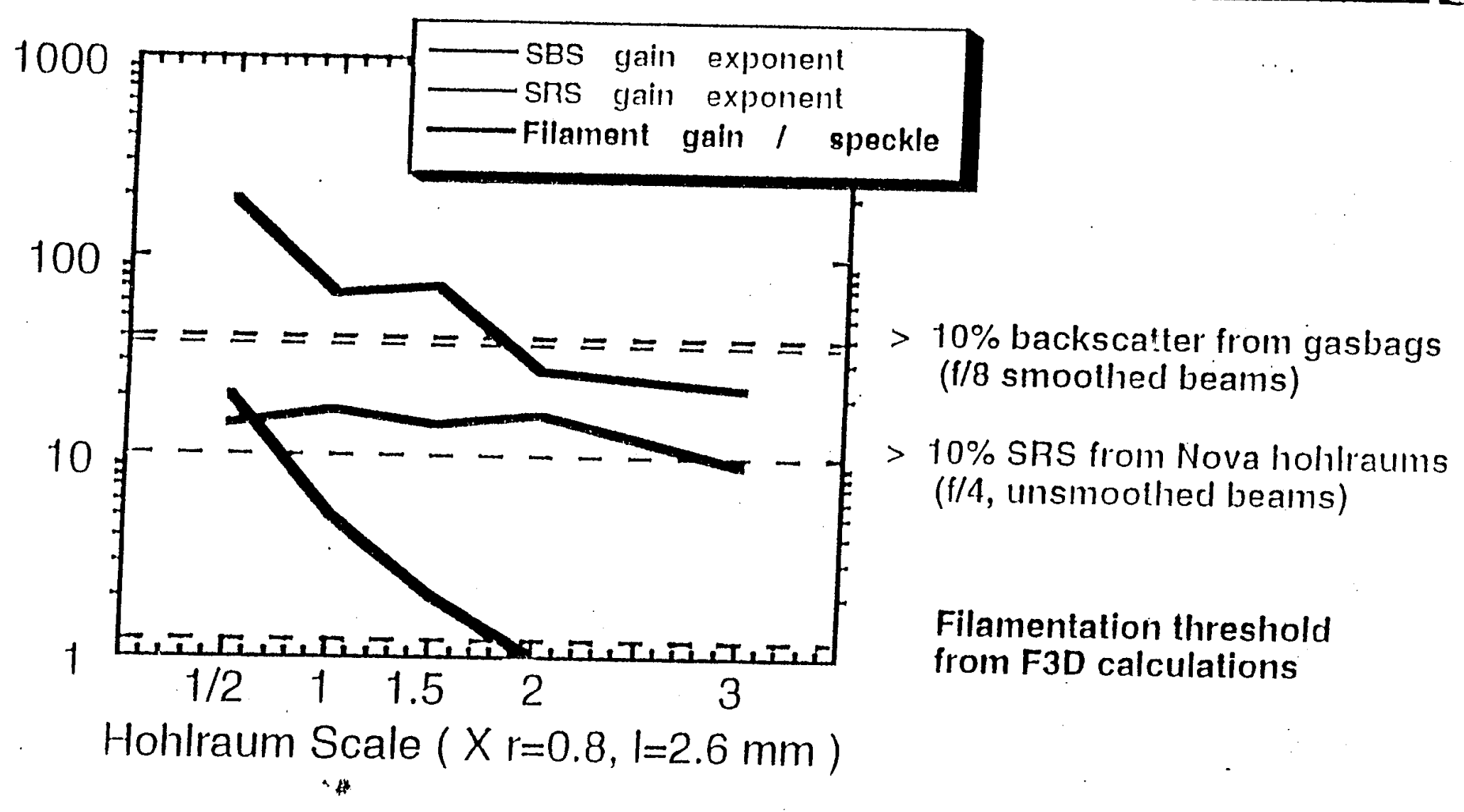

- $\quad$ SBS and filamentation gains decrease as hohlraum size increases due to lower intensity and fill density

- $\quad$ SRS gains scale weakly with target size because larger hohlraums have more plasma with $n_{e} \sim 20 \% n_{C}$ and are cooler 
Life times for NIF hohlraums depend on failure assumptions Life times for NIF hohlraums depend on failure assump

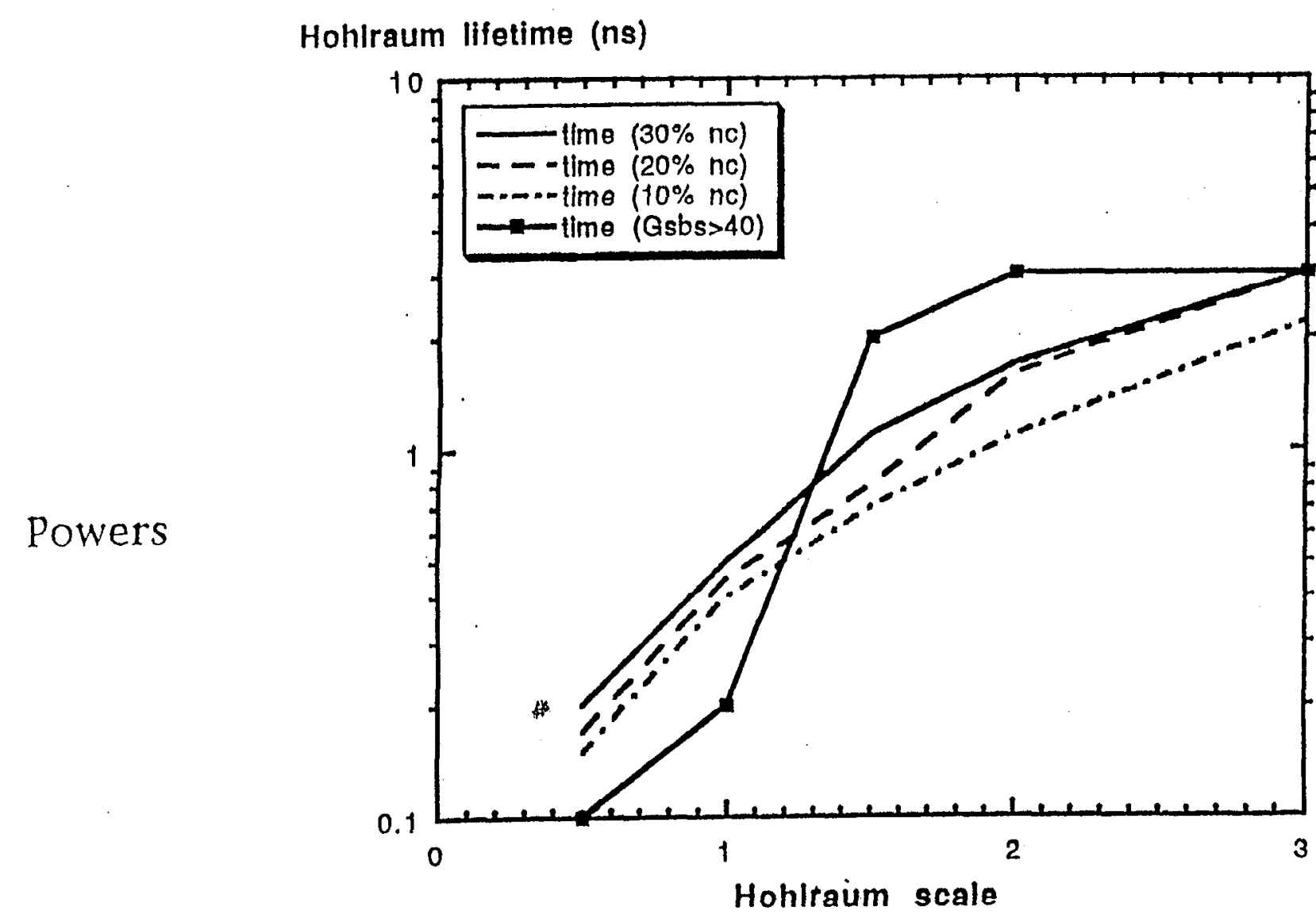




\section{Outline of Presentation}

*Nova experiments and scaling models indicate that higher temperature hohlraums are possible with NIF; these are valuable for SSMP

* Strongly-driven laser plasma interaction physics is a key issue for attaining higher temperature hohlraums

* Nova experiments and recent theory are hopeful: next steps are outlined 
Linear theory is only an indicator of when to worry

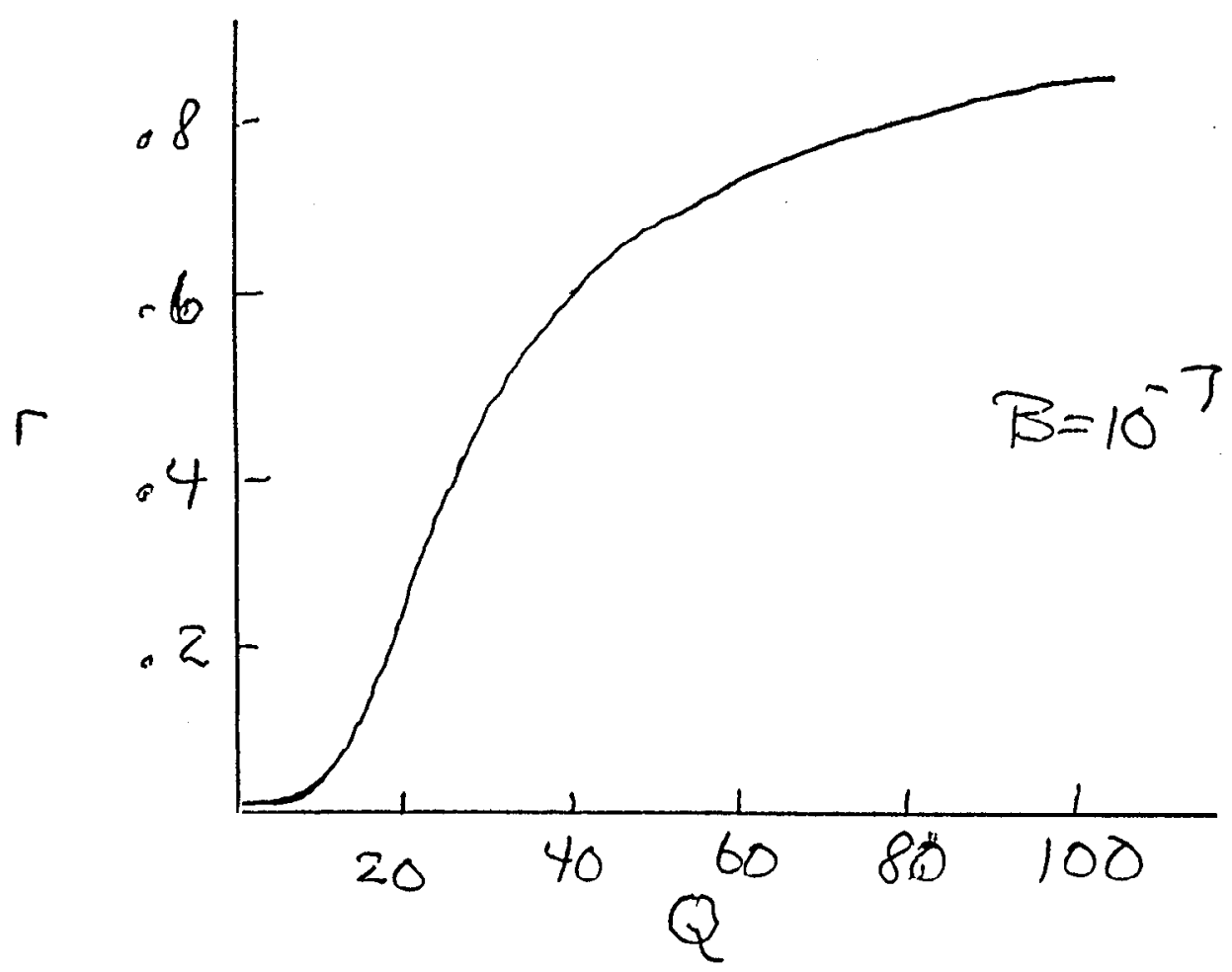

What we see in experiments is determined nonlinearly.

Example: gas bag Nova exeriments SRS $2 \times 1015 \mathrm{~W} / \mathrm{cm}^{2} \quad .12 \mathrm{ncr}$

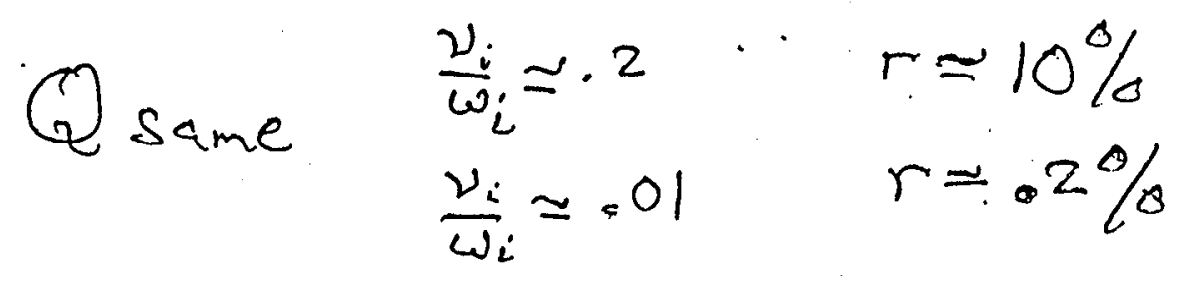


Nova small hohlraums test our understanding of high electron density and temperature plasma physics

Targets:

Scales $1,3 / 4,5 / 8,1 / 2,1 / 4$

(X $\mathrm{r}=0.8 \mathrm{~mm}, \mathrm{l}=2.75 \mathrm{~mm}$ )

Laser:

$25 \mathrm{TW} / 1 \mathrm{~ns}$ in 10 beams

Spotsize at best focus $\sim 80$ microns

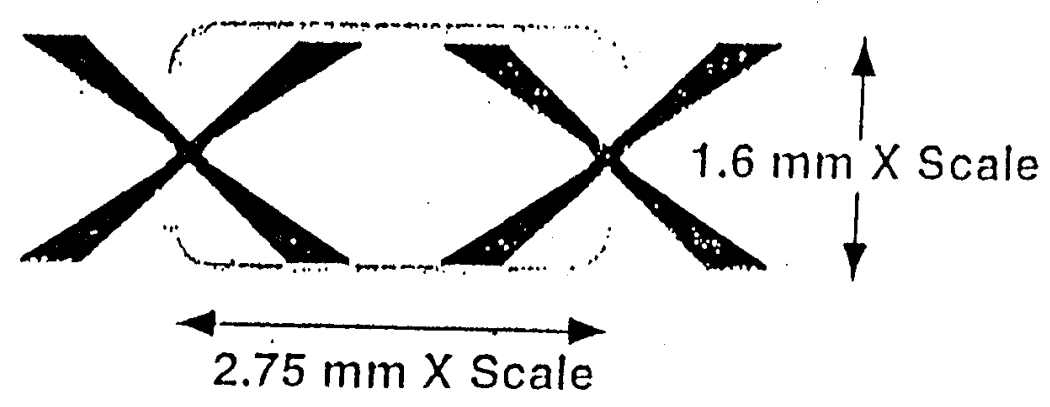

The fill plasma in these taryets is hot and dense by the time of peak radiation flux

Nova Scale $3 / 4, t=1$ ns

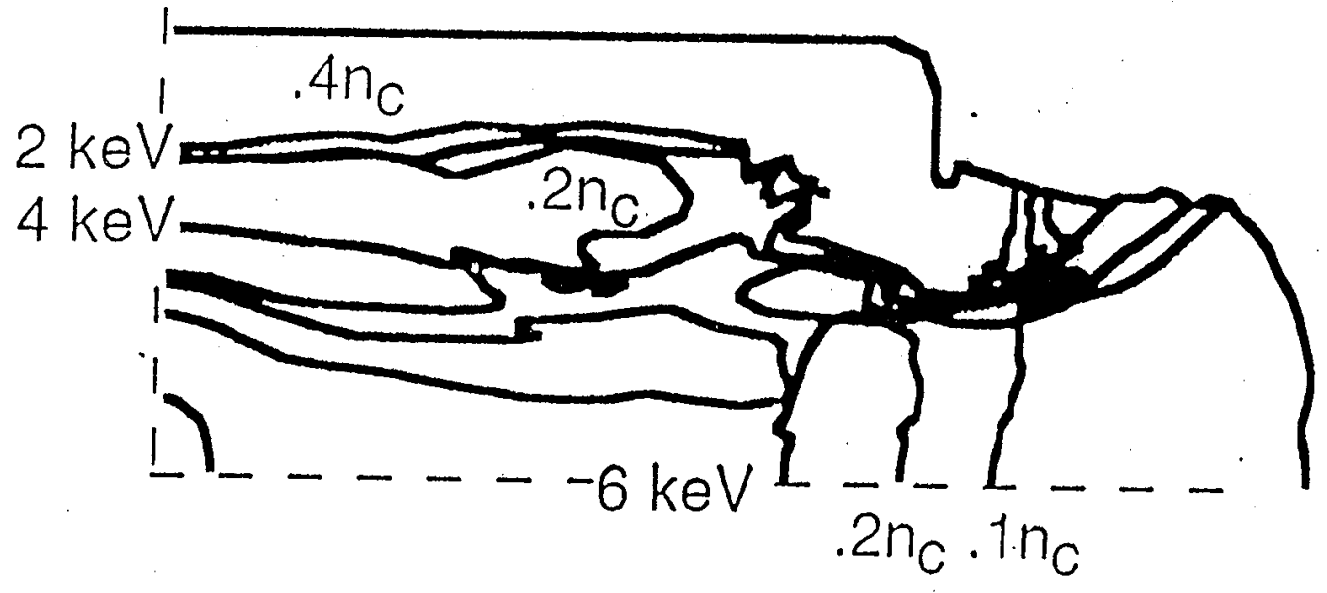




\section{Nova small hohlraums test density and temperature constraints for NIF hohlraum designs}

Small hohlraums on Nova allow us to access fill densities, plasma temperatures, and radiation temperatures that exceed those in the baseline NIF ignition designs
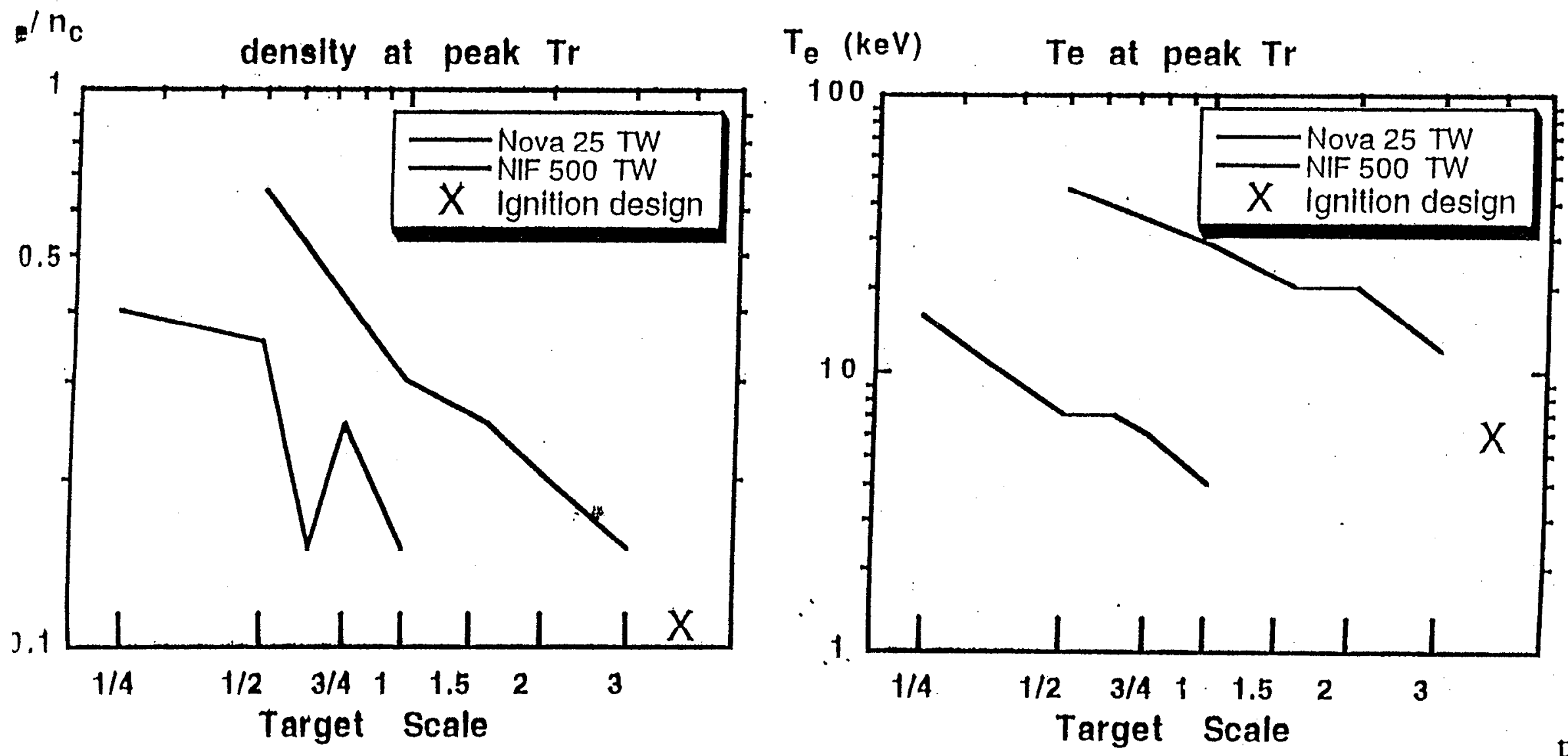
The SBS levels in the size scaling experiments were low

Targets:

Scales $1,3 / 4,5 / 8,1 / 2,1 / 4$

(X $r=0.8 \mathrm{~mm}, l=2.75 \mathrm{~mm}$ )

Laser:

$25 \mathrm{TW} / 1 \mathrm{~ns}$ in 10 beams

Spolsize at best focus $\sim 80$ microns

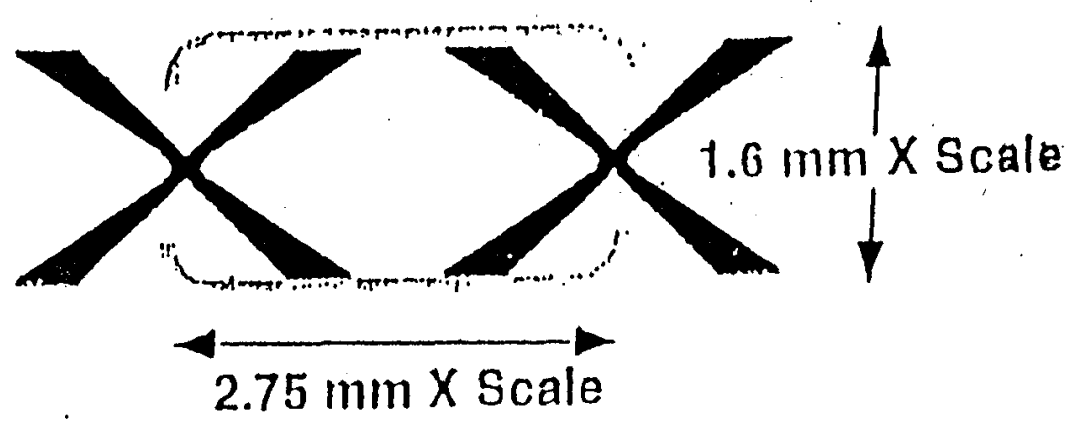

hohlraum

scale-1 (w/o 巾-plate)

scale-1 (p-plate)

scale-3/4 (w/o w-plate)

scale-3/4 ( $\psi-$ plate $)$

scale-5/0 (w/o w-plate)

scale-5/8 ( $(-$ plate)
FABS

$20 \mathrm{~J}$

$14 \mathrm{~J}$

$20 \mathrm{~J}$

$32 \mathrm{~J}$

$53 \mathrm{~J}$

$36 \mathrm{~J}$
$\mathrm{FABS}+\mathrm{NBI}$

$32 \mathrm{~J}$

$32 \mathrm{~J}$

$70 \mathrm{~J}$

$76 \mathrm{~J}$

$140 \mathrm{~J}$

out of $\sim 1400 \mathrm{~J}$

Laser beams facused in the LEH 


\section{The measured SBS backscatter fraction is $<5 \%$ for Scale 3/4 hohlraums}

- Linear gain calculations predict large gains and reflectivities

calculated SBS gain coefficient

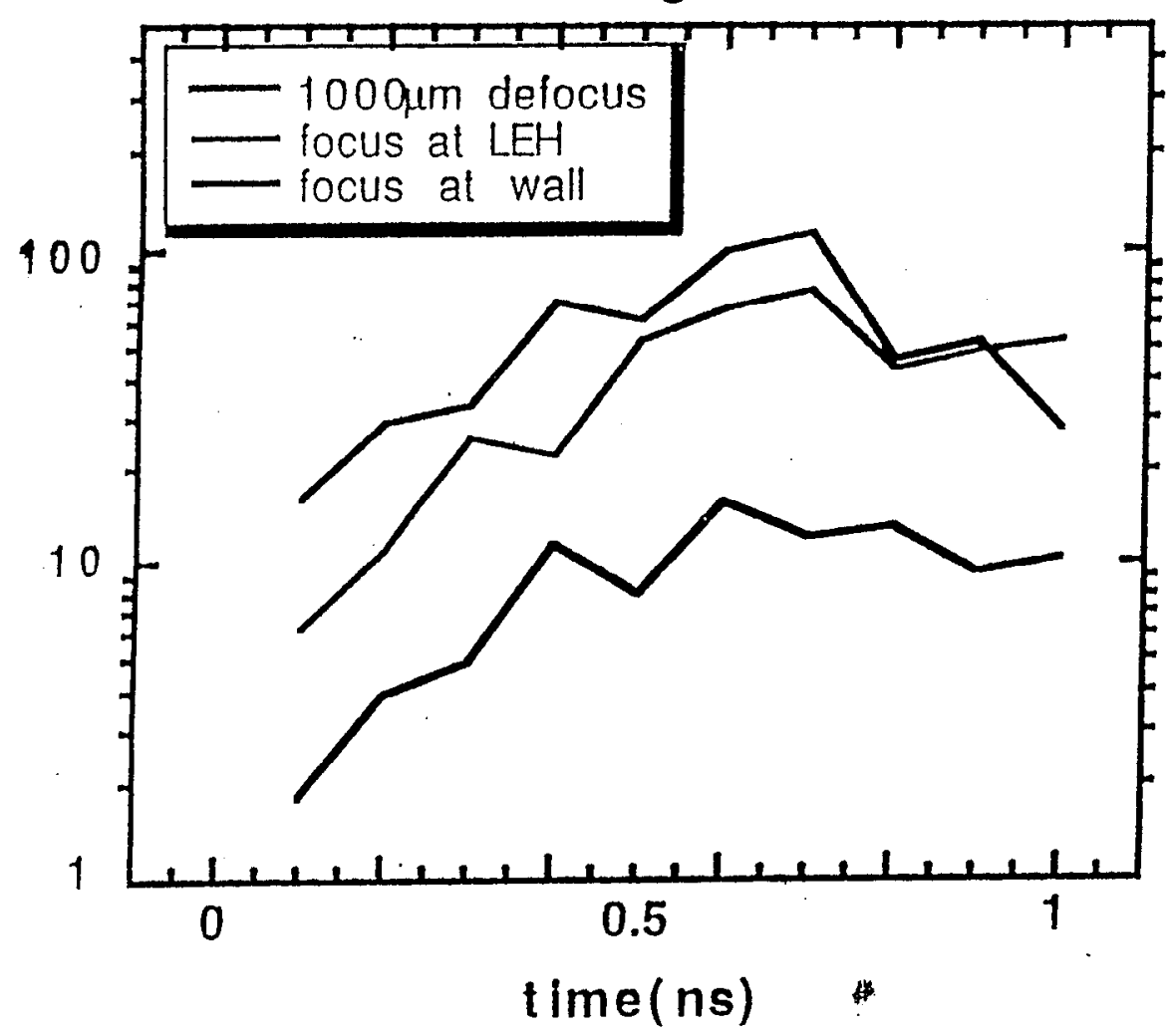

calculated SBS backscatter fraction

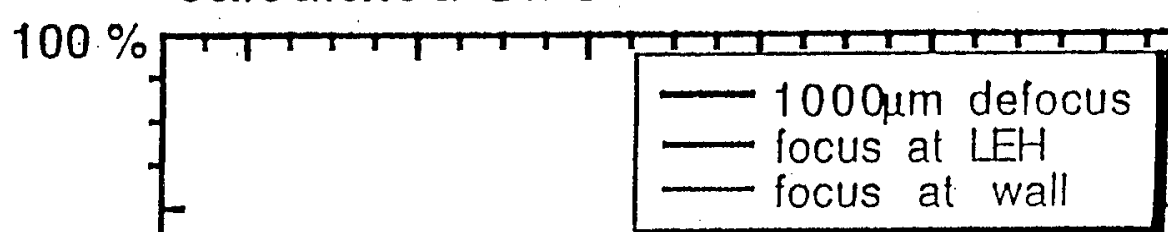

- $\quad$ SBS may be suppressed by SRS through pump depletion and/or Langmuir wave decay instabilities.

- filamentation may reduce the effective intensity by spraying the beam 


\section{SRS was sizeable with unsmoothed beams, but much reduced with RPP smoothed beams}

\begin{tabular}{|c|c|c|c|c|c|c|}
\hline hlraum size/focus & $T_{\text {wall }}$ & $T_{\text {hol }}$ & $E_{1101}$ & $E_{L}$ & $\mathrm{E}_{\mathrm{srs}} /$ bea & $E_{s b s} /$ beam \\
\hline 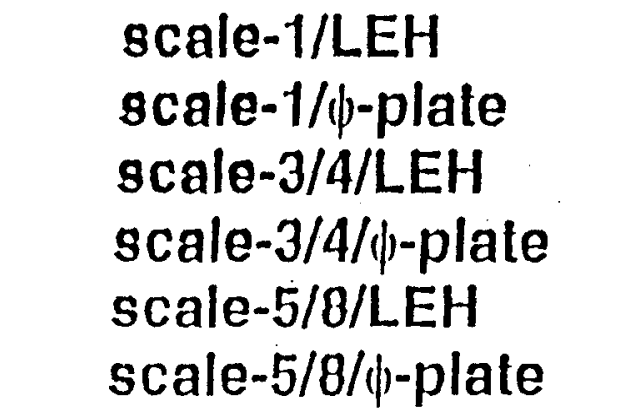 & $\begin{array}{l}241 \mathrm{eV} \\
243 \mathrm{eV} \\
273 \mathrm{eV} \\
261 \mathrm{eV} \\
282 \mathrm{eV} \\
279 \mathrm{eV}\end{array}$ & $\begin{array}{l}41 \mathrm{keV} \\
36 \mathrm{keV} \\
36 \mathrm{keV} \\
38 \mathrm{keV} \\
40 \mathrm{keV} \\
40 \mathrm{keV}\end{array}$ & $\begin{array}{l}518 \mathrm{~J} \\
422 \mathrm{~J} \\
1.3 \mathrm{~kJ} \\
850 \mathrm{~J} \\
1.3 \mathrm{~kJ} \\
1.0 \mathrm{~kJ}\end{array}$ & $\begin{array}{l}28 \mathrm{~kJ} \\
27 \mathrm{~kJ} \\
28 \mathrm{~kJ} \\
28 \mathrm{~kJ} \\
29 \mathrm{~kJ} \\
29 \mathrm{~kJ}\end{array}$ & $\begin{array}{r}437 \mathrm{~J} \\
26 \mathrm{~J} \\
455 \mathrm{~J} \\
48 \mathrm{~J} \\
394 \mathrm{~J} \\
175 \mathrm{~J}\end{array}$ & $\begin{array}{r}32 \mathrm{~J} \\
32 \mathrm{~J} \\
78 \mathrm{~J} \\
76 \mathrm{~J} \\
140 \mathrm{~J} \\
90 \mathrm{~J}\end{array}$ \\
\hline $\begin{array}{l}\text { scale- } 1 /-1000 \mu \mathrm{m} \\
\text { scale-1/LEH } \\
\text { scale-1/wall }\end{array}$ & $\begin{array}{l}242 \mathrm{eV} \\
233 \mathrm{eV} \\
234 \mathrm{eV}\end{array}$ & $\begin{array}{l}38 \mathrm{keV} \\
41 \mathrm{keV} \\
55 \mathrm{keV}\end{array}$ & $\begin{array}{l}40 \mathrm{~J} \\
230 \mathrm{~J} \\
390 \mathrm{~J}\end{array}$ & $\begin{array}{l}26 \mathrm{~kJ} \\
27 \mathrm{~kJ} \\
29 \mathrm{~kJ}\end{array}$ & $\begin{array}{l}78 \mathrm{~J} \\
245 \mathrm{~J} \\
520 \mathrm{~J}\end{array}$ & $\begin{array}{l}12 \mathrm{~J} \\
20 \mathrm{~J} \\
76 \mathrm{~J}\end{array}$ \\
\hline $\begin{array}{l}\text { scale-3/4/-1000 } \mu \mathrm{m} \\
\text { scale-3/4/LEH } \\
\text { scale-3/4/wall }\end{array}$ & $\begin{array}{r}254 \mathrm{eV} \\
* 259 \mathrm{eV} \\
" 243 \mathrm{eV}\end{array}$ & $\begin{array}{l}39 \mathrm{keV} \\
40 \mathrm{keV} \\
56 \mathrm{keV}\end{array}$ & $\begin{array}{l}400 \mathrm{~J} \\
940 \mathrm{~J} \\
490 \mathrm{~J}\end{array}$ & $\begin{array}{l}26 \mathrm{~kJ} \\
27 \mathrm{~kJ} \\
27 \mathrm{~kJ}\end{array}$ & $\begin{array}{l}130 \mathrm{~J} \\
420 \mathrm{~J} \\
430 \mathrm{~J}\end{array}$ & $\begin{array}{r}36 \mathrm{~J} \\
110 \mathrm{~J} \\
50 \mathrm{~J}\end{array}$ \\
\hline
\end{tabular}




\section{When SRS losses are taken into account, measured and calculated hohlraum temperatures agree for hohlraum scales $>5 / 8$ :}

- The calculated interior hohlraum $\operatorname{Tr}$ is $15-20 \%$ higher

than the wall temperature at the midplane

- The Scale 5/8 Tr peaks before the end of the laser pulse (diagnostic hole closure?)

Tr at midplane

from Dante

Position of best focus:

O wall

口 LEH

A 1000 microns outside LEH

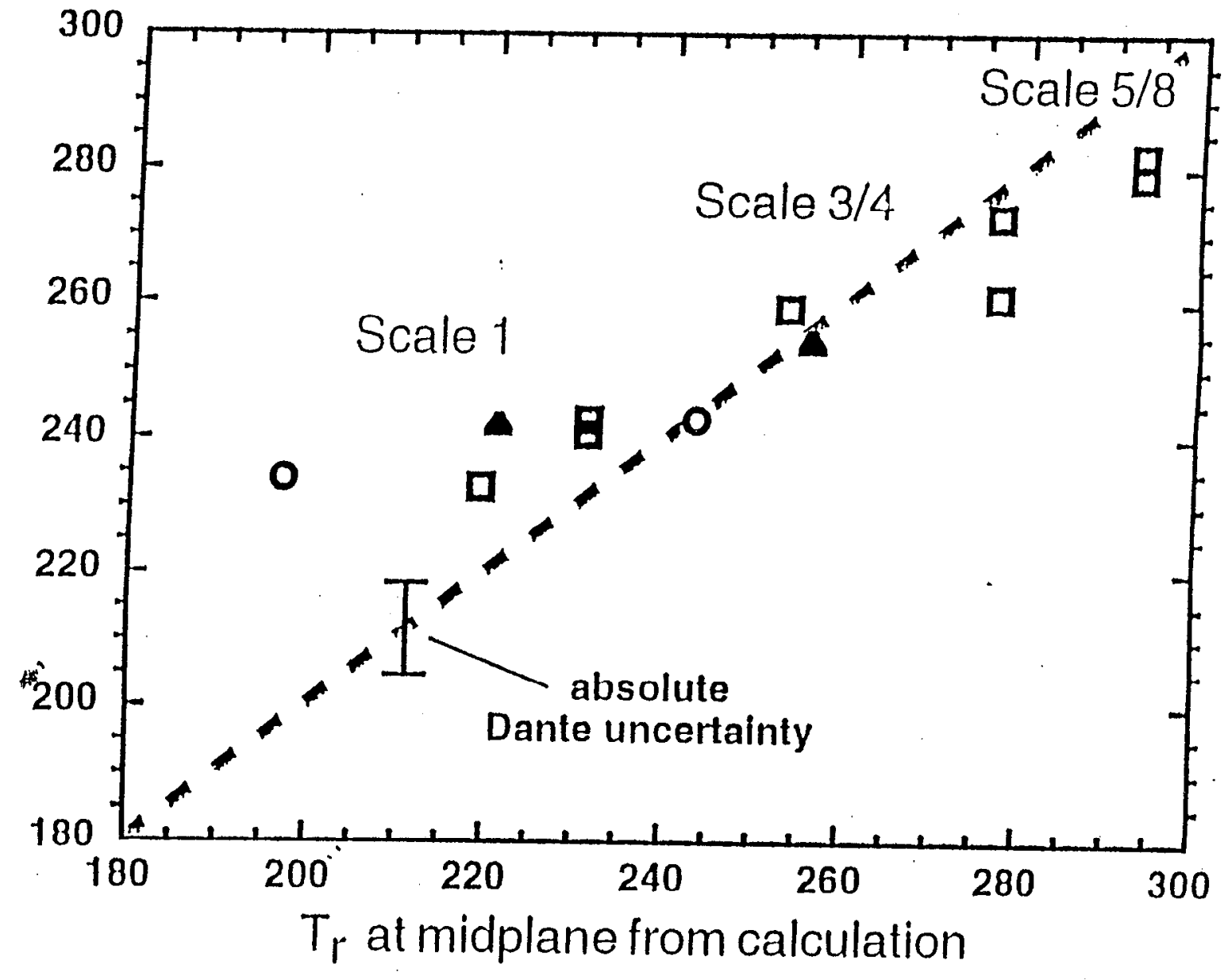




\section{Filling to $n_{e}>n_{c} / 4$ results in qualitatively different SRS behavior in the Scale 1/4 Nova hohlraum}

- When the hohlraum fill density exceeds $n_{C} / 4$, the length of plasma that supports SRS is short

- $\quad$ Strong filamentation would create density depressions with $n_{e}<n_{C} / 4$ (not in calculations)

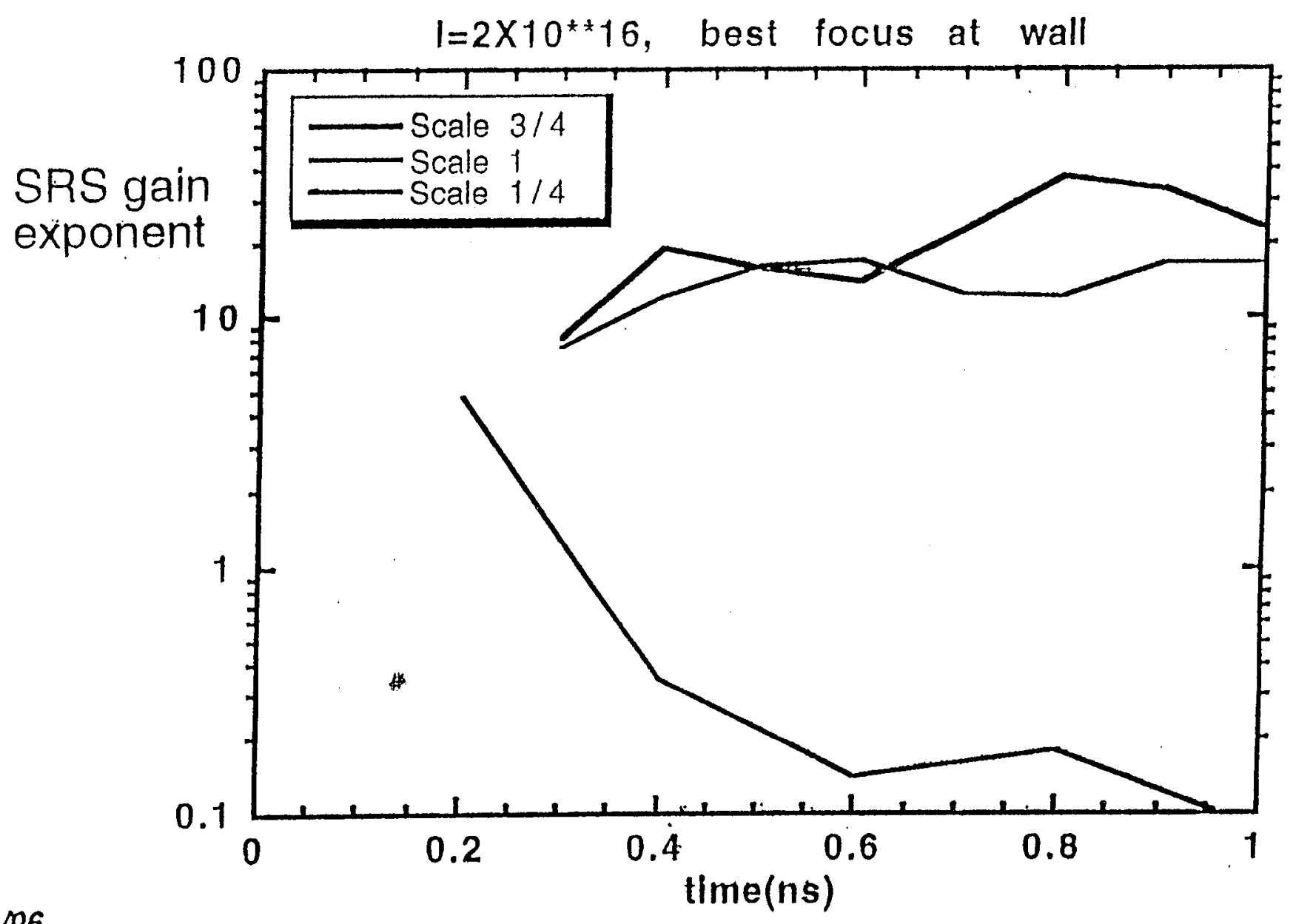




\section{Backscattered Energy has been measured very low on axis}

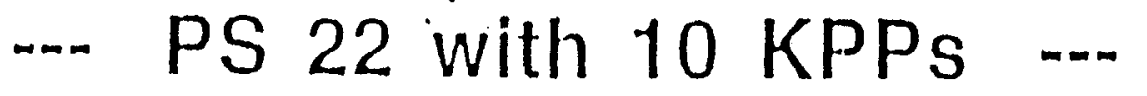

Similar results

with shipid pultses

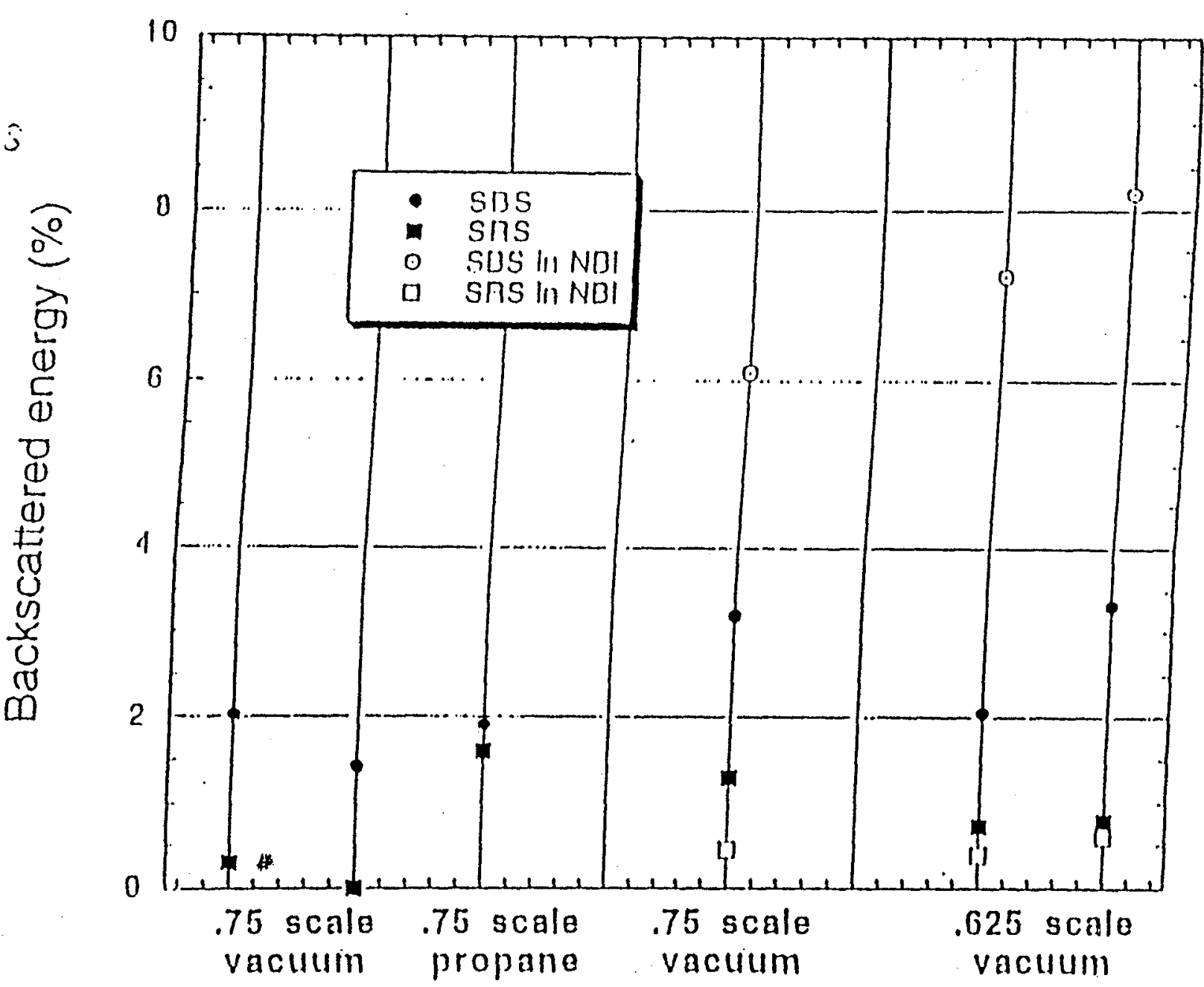

Brillouin near backscatter seems to be higher

We have to reprocess the data with recent FABS diode calibration

N. Dague et al, 1997 . 


\section{A nonlinear scaling model for strongly- driven SBS has been proposed}

Better agreement with observed dependences of SBS reflectivity on intensity, plasma density, length, and $f$ number

See manuscript by Kruer et al

Improved calculations are needed 


\section{- n.... me rep. \\ 1998 ICPP}

$$
\text { Plasuar Plasies and Contralled fusion }
$$

Strongly-Driven Laser Plasma Coupling

W. L. Kruer, E.M. Campbell, C.D. Decker, S.C. Wilks, J. Moody, T.

Orzechowski, L. Powers, L. J. Suter

Lawrence Livermore National Laboratory, P.O. Box 808, Livermore, California 94550

B.B. Afeyan

Polymath Associates

N. Dague

Commissariat a l'Energie Atomique, Bruyeres-le-Chatel

\section{Abstract}

An improved understanding of strongly-driven laser plasma coupling is important for optimal use of the National Ignition Facility (NIF) for both inertial fusion and for a variety of advanced applications. Such applications range from high energy $x$ ray sources and high temperature hohlraums to fast ignition and laser radiography. We discuss a novel model for the scaling of strongly-driven stimulated Brillouin and Raman scattering. This model postulates an intensity dependent correlation length associated with spatial incoherence due to filamentation and stimulated forward scattering. We first motivate the model and then relate it to a variety of experiments. Particular attention is paid to high temperature hohlraum experiments, which exhibited low to modest stimulated Brillouin scattering even though this instability was strongly driven. We also briefly discuss the strongly nonlinear interaction physics for efficient generation of high energy electrons either by irradiating a large plasma with near quarter-critical density or by irradiating overdense targets with ultra intense laser light.

\section{Introduction}

The coupling of intense laser light with plasmas is an extremely rich and challenging topic. The coupling mechanisms ${ }^{1}$ span the gamut from inverse bremssthralung and linear mode conversion to many nonlinear optical processes. These include stimulated Raman scattering (SRS) from electron plasma waves, stimulated Brillouin scattering (SBS) from ion sound waves, and laser beam self-focusing and filamentation. These processes depend upon laser intensity and produce effects such as changes in the efficiency and location of the absorption and generation of very energetic electrons. Depending on the application, one wishes to either minimize or maximize various nonlinear processes.

Laser plasma coupling is a very important constraint for the conventional approach to inertial fusion. Figure 1 is a schematic showing the 


\section{Nova experiments are hopeful}

Nonlinear scaling model is hopeful

Key question: what happens in

NIF scale 1? (4x larger than related nova experiment)

:4

Some next steps are outlined 
This strongly-driven regime is relatively unexplored

$$
\mathrm{n} \gtrsim .25 \mathrm{ncr} \quad \mathrm{Te} \sim 15-20 \mathrm{kev}
$$

Both SBS and Filamentation very strongly driven

$\mathrm{Z}(\mathrm{vos} / \mathrm{ve})^{2}>1 \quad(>>1$ in higher intensity speckles)

Plasma issues include

Interplay between SBS and Filamentation--SBS levels

2D and 3D Hybrid PIC simulations and F3D

Ion-ion collisions, effect of interpenetrating plasmas on hohlraum plasma conditions

Rambo codes with collisions a la Rambo PRL

Modified electron distributions, effects on inverse bremsstrahling and speckle decorrelation Fokker-Planck calculations a la Afeyan PRL 


\section{ZOHAR provides laser-plasma simulation at the most fundamental level of description.}

- Zohar's model equations ${ }^{1}$ provide a fully kinetic and nonlinear description:

Ampere-Faraday-Maxwell fields

Relativistic particle dynamics

Particle-in-cell coupling of particles to fields

- The BZohar package optimizes for Brillouin scatter². Substitutions:

high frequencies: time-enveloped fields and currents

low frequencies: nonlinear Boltzmann electrons + Poisson

Much-larger time steps resolve picoseconds rather than femtoseconds.

- Only Zohar provides first principles modeling of scattering instability saturation and laser-plasma interaction at very high intensities.

${ }^{1}$ As described in "Plasma Physics via Computer Simulation", Birdsall and Langdon.

2 "Resonantly Excited Nonlinear Ion Waves", B. 1. Cohen, B. F. Lasinski, A. B. Langdon, E.

A. Williams, Physics of Plasmas 4, 956-977 (1997). 
Moderate stimulated Raman scattering appears tolerable -LLNL

$$
\text { SRS } \quad \omega_{0}=\omega_{\mathrm{sc}}+\omega_{\mathrm{pe}}
$$

In very hot plasmas, SRS is mainly from $n \sim .2-.25 n_{\text {cr }}$

*significant absorption of scattered light

*most energy stays in hohlraum

*hot electrons may be useful (Suter)

SRS especially significant for hohlraums filling to $\sim .25 \mathrm{n}_{\text {cr }}$

Bonus: such experiments also relevant to hard x-ray sources for NWET 
A variety of experiments can be suggested.

A variety of experiment can

Janus Higher $\mathrm{Z}$ exploding

or Trident foil plasma with

$\mathrm{n}>.25 \mathrm{ncr}$ code test:

interplay of SBS and Fil.

simulate entire

experiment in $2 \mathrm{D}$
Nova or

Omega Upgrade smaller hohlraums with improved diagnostics denser gas bags

or with, say, 2 wo beam

to get $\mathrm{n}>.25 \mathrm{n}_{\mathrm{Cr}}$ 
Most of these topics are ideal for collaboration with Naval Postgraduate School students

Interface NPS students with Lab research projects

--Pool of talented, motivated students

--Very valuable to establish LLNL-NPS connections 
* Nova experiments and scaling models indicate that higher temperature hohlraums are possible with NIF; these are valuable for SSMP

* Strongly-driven laser plasma interaction physics is a key issue for attaining higher temperature hohlraums

*Nova experiments and recent theory are hopeful: next steps are outlined 


\section{Appendix}

A nọnlinear scaling model for strongly driven SBS 


\section{Towards a new scaling model.........}

- Linear scaling clearly does not generally work

$$
\mathrm{r} \sim \mathrm{B} \exp \left(\mathrm{k}^{*} \mathrm{I} * \mathrm{~L} / \mathrm{v}\right)
$$

sometimes qualitatively wrong

- Evolution in "improvements"

--speckle statistics (sum over intensity distribution)

Rose et al, ......

--damping not necessarily linear Landau damping

Rambo et al, Afeyan et al, Rozmus et al, ....

- Next step?----replace L with intensity-dependent correlation length

--instability-induced incoherence

--I*L statistics (Afeyan and Schmitt)

--spatial incoherence supprèsses and results from filamentation 


\section{An idealized model for SBS in strongly driven plasmas is illuminating-I}

Consider an RPP beam, SBS from heavily damped ion waves

Hypothesis I

Gain is limited by intensity-dependent coherence length $\left(\ell_{\text {coh }}\right)$; incoherent regions (different speckles) do not communicate

$$
r=\sum_{I} B \frac{L}{\ell_{\text {coh }}} \exp Q\left(I, \ell_{\text {coh }}\right)
$$

$\sum_{\text {I }}$ average over speckle statistics

$\mathrm{Q}=\frac{\pi}{2} \frac{\ell_{\mathrm{coh}}}{\lambda_{0}}\left(\frac{\omega_{\mathrm{pe}}}{\omega_{0}}\right)^{2}\left(\frac{\mathrm{v}_{\mathrm{os}}}{\mathrm{v}_{\mathrm{e}}}\right)^{2} / v_{\mathrm{i}} / \omega_{\mathrm{i}}$ 


\section{A simple model for SBS scaling-II}

\section{Hypothesis II}

- Coherence length in strongly driven plasma is set by filamentation (perhaps aided by Brillouin forward scattering)

Speckles: $r=f \lambda_{0}, \ell_{\text {coh }}=8 \mathrm{f}^{2} \lambda_{0}$

- Speckle self-focuses when $r_{\mathrm{SF}} \simeq 2 \mathrm{r} \frac{\mathrm{v}_{\mathrm{e}}}{\mathrm{v}_{\mathrm{OS}}} \frac{\omega_{0}}{\omega_{\mathrm{pe}}}<\ell_{\text {coh }}=8 \mathrm{f}^{2} \lambda_{0}$

- Self-focusing of speckles (filamentation) $\rightarrow$ angular spread

- Assume process goes to marginal stability

i.e., $\mathrm{r}_{\mathrm{SF}} \simeq \ell_{\mathrm{coh}} \bumpeq \mathrm{f} \simeq \frac{1}{4} \frac{\mathrm{v}_{\mathrm{e}}}{\mathrm{v}_{\mathrm{os}}} \frac{\omega_{0}}{\omega_{\mathrm{pe}}}, \ell_{\mathrm{coh}} \cong \frac{\lambda_{0}}{2}\left(\frac{\mathrm{v}_{\mathrm{e}}}{\mathrm{v}_{\mathrm{OS}}}\right)^{2}\left(\frac{\omega_{0}}{\omega_{\mathrm{pe}}}\right)^{2}$ 


\section{This model gives scalings closer to strongly} driven experiments

$$
\text { With } \begin{aligned}
\ell_{\mathrm{coh}} & \simeq \frac{\lambda_{0}}{2}\left(\frac{\mathrm{v}_{\mathrm{e}}}{\mathrm{v}_{\mathrm{os}}}\right)^{2}\left(\frac{\omega_{0}}{\omega_{\mathrm{pe}}}\right)^{2} \\
\mathrm{Q} & \rightarrow \frac{\pi}{4} / \frac{v_{\mathrm{i}}}{\omega_{\mathrm{i}}} \\
\mathrm{r} & \sim \mathrm{B} \frac{\mathrm{n}}{\mathrm{n}_{\mathrm{cr}}} \frac{\mathrm{L}}{\lambda_{0}}\left(\frac{\mathrm{v}_{\mathrm{os}}}{\mathrm{v}_{\mathrm{e}}}\right)^{2} \exp \left[\frac{\pi}{4} / \frac{v_{\mathrm{i}}}{\omega_{\mathrm{i}}}\right]
\end{aligned}
$$

Note weak scaling with $\mathrm{n}, \mathrm{I}, \mathrm{L}$ 
The scaling with damping is qualitatively consistent with experiments

- the reflection decreases with damping

D. Montgomery et al, PP (1998) and references therein

- numbers require better understanding of the self-consistent damping and detuning, which depends on

--fluctuations --modified distributions

--collisions --plasma composition and mixing

- modest reflectivies can be motivated

Au plasma n .2ncr L set by absorption length $300 \mu$

coherence length $40 \mu<\mathrm{dv}>\sim .05 \quad \mathrm{~B} \sim 10^{-8} \quad \mathrm{r} \sim 5 \%$ 
Issues for model evolution:

\section{LLNL}

*when are "speckles" decorrelated?

-modified distributions and nonlocal transport can play a role

* coherence leng th as a function of intensity

-role of filamentation, Instability of filaments, induced gradients, etc.

* self-consistent damping, collisional effects

* detuning by long wavelength fluctuations

* role of plasma-induced spatial incoherence

*noise levels

Some relevant preprints and reprints are avallable 
Speckles are decoupled by, say, modified distribution functions which change the ion wave frequency

- The next speckle after an intense one most likely has a much smaller intensity

- Heat transport or collisional absorption can produce an intensity-dependent modified electron distribution function, which changes the ion wave frequency

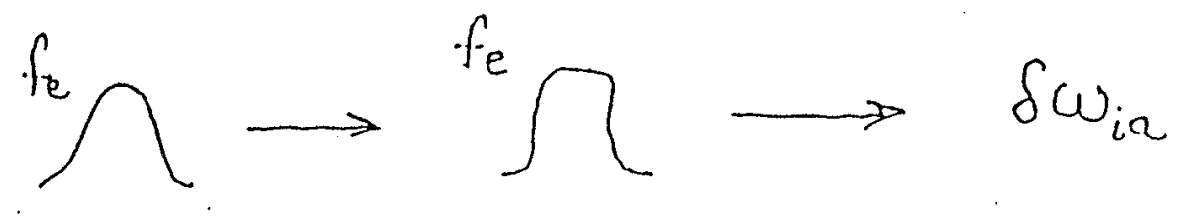

- Variation*of the ion wave frequency from one speckle to another disrupts their communication

B.B.Afeyan et. al. PRL 80, 2322 (1998) 
In Flat Top Distribution Functions Ions Are Not As Well Shiclded: Increased Effective Electron Tempcrature T $\mathrm{T}_{\mathrm{v}}$. $\mathrm{Or}_{\mathrm{s}} \mathrm{c}_{\mathrm{s}}{ }^{2}$ for IAWs

$c_{s}^{2} l_{\| l i l-|n|)}=C_{e f f}^{2} c_{s}^{2} I_{\text {Maxwellian }}$

$$
C_{e f f}^{2}=\left[\frac{3 \Gamma^{2}(3 / n)}{\Gamma(1 / n) \Gamma(5 / n)}\right]
$$

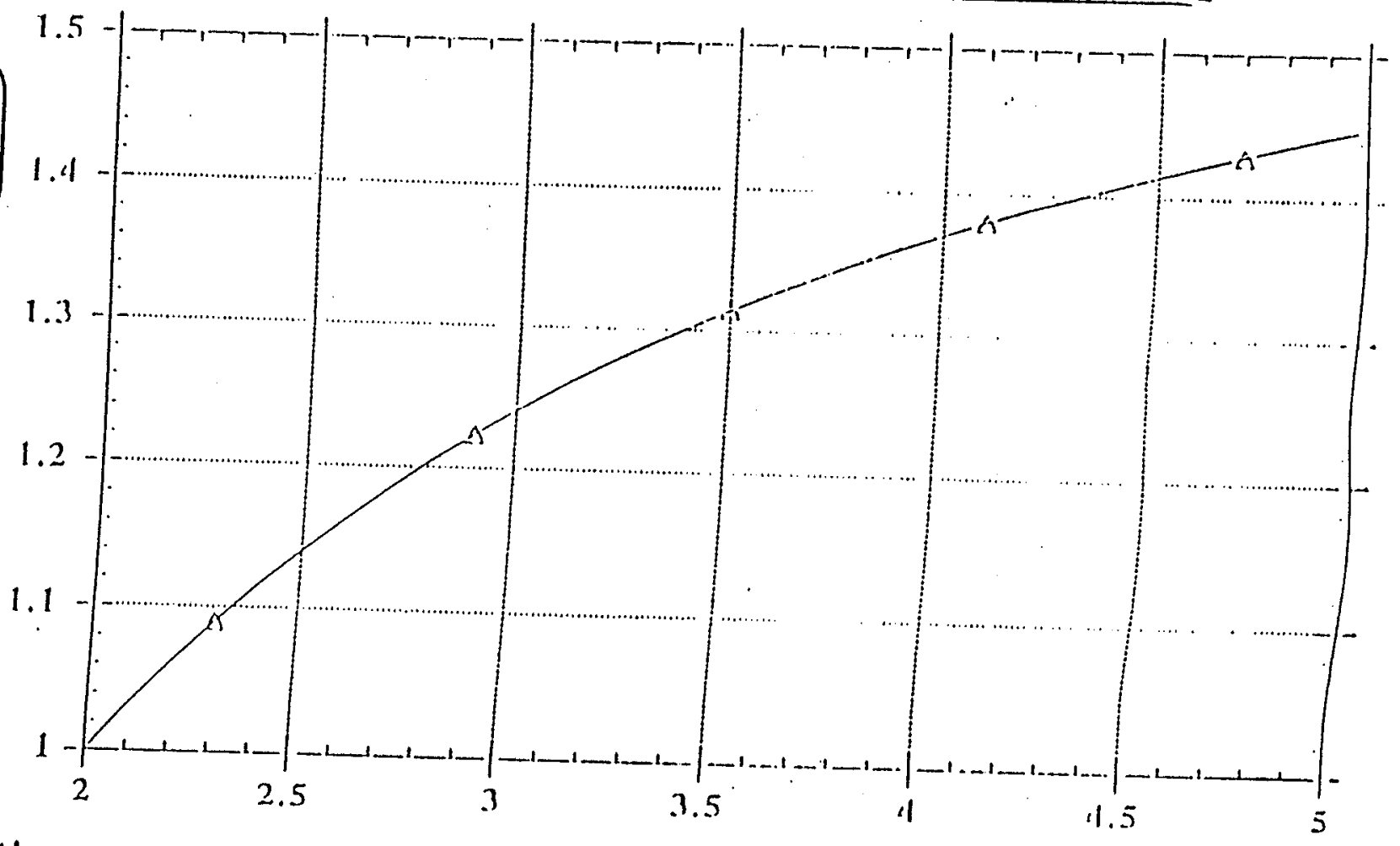

- The frecluencies of ion acouslic waves can be strelched by as much as $20 \%$ duc to the lattening of the central part of the electron distribution function.

- Passage through regions with various degrecs of flattened distriluntion lunclions could scrve as a an additional detuning or saturation mechanism l'or siBS and LDD . Strongly discriminate against oblique propagation $=\Rightarrow$ reduce crossed berm gain.

- RPP beams, speckle patterns and enhancements thereof duc to filamentation can casily provide the c ${ }_{s}^{2}$ varying medium where SIBS gain would be limited. 
Other effects contribute to decorrelating speckles and reducing the coherence length

- thermal filamentation

- stimulated Brillouin forward scattering

also gives laser beam spraying

see experiments by J. Moody and by P. Young

- temporal incoherence

for example, by SSD

speckles move in time

- fluctuations,........ 